\title{
Intravital fluorescence facilitates measurement of multiple physiologic functions and gene expression in tumors of live animals
}

\author{
Mark W. Dewhirst ${ }^{\mathrm{a}, \mathrm{b}, *}$, S. Shan ${ }^{\mathrm{a}}$, Yiting Cao ${ }^{\mathrm{a}}$, Benjamin Moeller ${ }^{\mathrm{a}}$, Fan Yuan ${ }^{\mathrm{b}}$ and Chuan-Yuan $\mathrm{Li}^{\mathrm{a}}$ \\ ${ }^{a}$ Department of Radiation Oncology, Duke University Medical Center, Durham, NC 27710, USA \\ ${ }^{\mathrm{b}}$ Department of Biomedical Engineering, Duke University, Durham, NC 27710, USA
}

\begin{abstract}
The purpose of this report is to present an overview of the use of fluorescence imaging in vivo, with particular emphasis on oncology. It is important to note, however, that many of the methods described herein have been applied to the study of non-malignant tissues as well. Modern medicine and biology research has benefited greatly from an ever-expanding assortment of fluorescent markers and labels. These markers and labels have allowed investigators to observe the behavior and properties of cell and molecular entities of interest in the context of complicated biological systems such as a mammalian cell or a whole mouse. Methods developed to image fluorescence in whole mice have been valuable in studying patterns of tumor growth and metastases. Alternatively, more detailed information and a wide variety of endpoints can be obtained using "intravital" preparations. This review focuses on use of fluorescence imaging for intravital preparations. For detail on fluorescence imaging of whole animals, refer to reviews on this subject $[1,2]$. For oncologic applications, studies have focused primarily on window chamber preparations that allow for real-time visualization of tumor growth, vascularity, vascular responses to stimulation, vascular permeability, vascular orientation, flow instability, and the like. These endpoints have been used to show that there are functional differences between tumor and normal tissues with respect to these functions under baseline conditions and after therapeutic manipulation. Examples of some of these differences are provided in this review as a means to illustrate how they can be used.
\end{abstract}

\section{Introduction}

Intravital fluorescence microscopy has been used for a wide variety of applications in oncology. The applications are limited only by the imagination of the investigator in developing methods to visualize various physiologic and cellular functions. The data that can be derived from such studies can be used to establish fundamental characteristics of microcirculatory behavior that influence solute transport, such as oxygen, hydrogen ions, and drugs. Studies of leukocyte-endothelial

* Corresponding author: Department of Radiation Oncology, Duke University Medical Center, Research Drive, Room 201 MSRB, Box 3455 DUMC, Durham, NC 27710, USA. Tel.: +1 919694 4180; Fax: +1 919684 8718; E-mail: dewhirst@ radonc.duke.edu. cell interactions provide valuable insight into regulation of inflammation and immunologic reactions in tumors and how such effects can be modulated. Novel insights into the evolution of tumor angiogenesis and interactions between tumor and host cells have been reported.

An important development in the past 30 years has been the use of fluorescent 'reporter' genes to monitor the production and metabolism of proteins. The advent of the green fluorescence protein in the early 1990s heralded a new era in fluorescent labeling of proteins. For the first time, it was possible to label and monitor the behavior of individual proteins non-invasively and continuously. Additionally, this type of reporter has been used extensively as a means to study the biology of metastasis, yielding unprecedented clarity about this 
process in a variety of metastatic sites. The original protein now has been modified so that several varieties are available that fluoresce at different wavelengths. This has allowed for simultaneous observation of more than one reporter at a time in the same experiment. In this review, we summarize currently available variants of the green fluorescent protein (GFP) and their potential applications in molecular medicine, with a special emphasis on applications in tumor angiogenesis and physiologic studies.

\section{Intravital tissue models}

An excellent recent review surveys window chamber methods and optical means to study them [3]. A brief summary is provided here, with emphasis on use of fluorescence microscopy. Acute preparations have been used that involve surgical exposure of a tissue surface, such as cremaster muscle [4,5], choroid [6], or mesentery [7]. Such methods are relatively easy to develop and use but are not easily amenable to the study of tumors because they would require tumor growth prior to exteriorization of the tissue for visualization. Because of their exposure to the environment once they are created, they cannot be used more than once on the same animal. Despite the limitations, valuable data on microcirculatory function has been obtained from tumor transplantation in the choroid [8], the cremaster muscle fascia $[9,10]$ and intradermal sites [11]. One acute model that has been used quite successfully to study tumor metastatic behavior is the liver. For this application, the liver is exteriorized and visualized ventrally, using an inverted microscope [12].

Window chamber models, on the other hand, are surgically prepared and the exposed tissues are covered by glass or plastic. Therefore, long-term observation over many days to weeks can be accomplished in the same subject. The most commonly used windows are implanted in dorsal skin flaps of rats, hamsters, or mice (immunocompetent and immunocompromised) [13-16]. They are made by removing the epidermal layer of skin from one or both surfaces of the skin flap as it is elevated dorsally from the back of the animal. Once the epidermis is removed, the flap is sutured to a metallic or plastic frame in which the exposed tissue is covered by glass (Fig. 1(A)). Rabbit ear chambers and hamster cheek pouches also have been used $[17,18]$. All of these preparations utilize subcutaneous or submucosal tissue to support tumor growth. It is well known that the phenotype of tumors is af- fected by the tissue in which the tumors have been transplanted and, typically, growth and physiologic function in orthotopic sites is different from subcutaneous sites [19]. Orthotopic windows have been developed for the brain $[19,20]$, mammary gland (Shan and Dewhirst, unpublished data) and pancreas [21], which should allow for characterization of tumor growth and behavior in these orthotopic sites (Fig. 1(B)).

Window chamber models have significant disadvantages. They are technically difficult to implant and maintain and require specialized microsurgical skills and materials for making the chamber preparations. Specialized animal housing at elevated temperatures may be required to facilitate tumor growth $[22,23]$. The tumors are small (typically 2-3 mm diameter and less than $500 \mu \mathrm{m}$ thick), and one could argue that they may not fully represent issues governing solute transport and other physiologic functions in larger tumors. Additionally, intravital microscopy requires specialized optics, such as long working distance objectives and sophisticated image acquisition and analysis hardware and software. Because of their complexity, window chamber models do not lend themselves to studies for screening therapeutic agents. However, they may be useful for determining how therapeutic strategies work.

In many cases, however, the advantages of these models outweigh the disadvantages. One cannot underestimate the value and power of being able to monitor serially the same preparation over time. This feature facilitates solute transport measurements, study of antiangiogenic or vascular targeting therapies, and evaluation of the physiologic consequences of therapies such as radiation, chemotherapy, and immunotherapy. The development of fluorescent reporter genes in the past several years has revolutionized the use of these models. Now it is possible literally to study changes in gene expression during tumor growth or in response to treatment. There is no substitute for direct measurement of these parameters as opposed to using indirect evaluation of these effects. Several examples of these types of studies are provided below.

\section{Green fluorescent proteins}

\subsection{Different green fluorescent protein variants and their physical characteristics}

The GFP initially was discovered in 1962 by Shimomura and colleagues from the jellyfish Aequorea victoria during their study of aequorin, a $\mathrm{Ca}^{2+}$-activated 

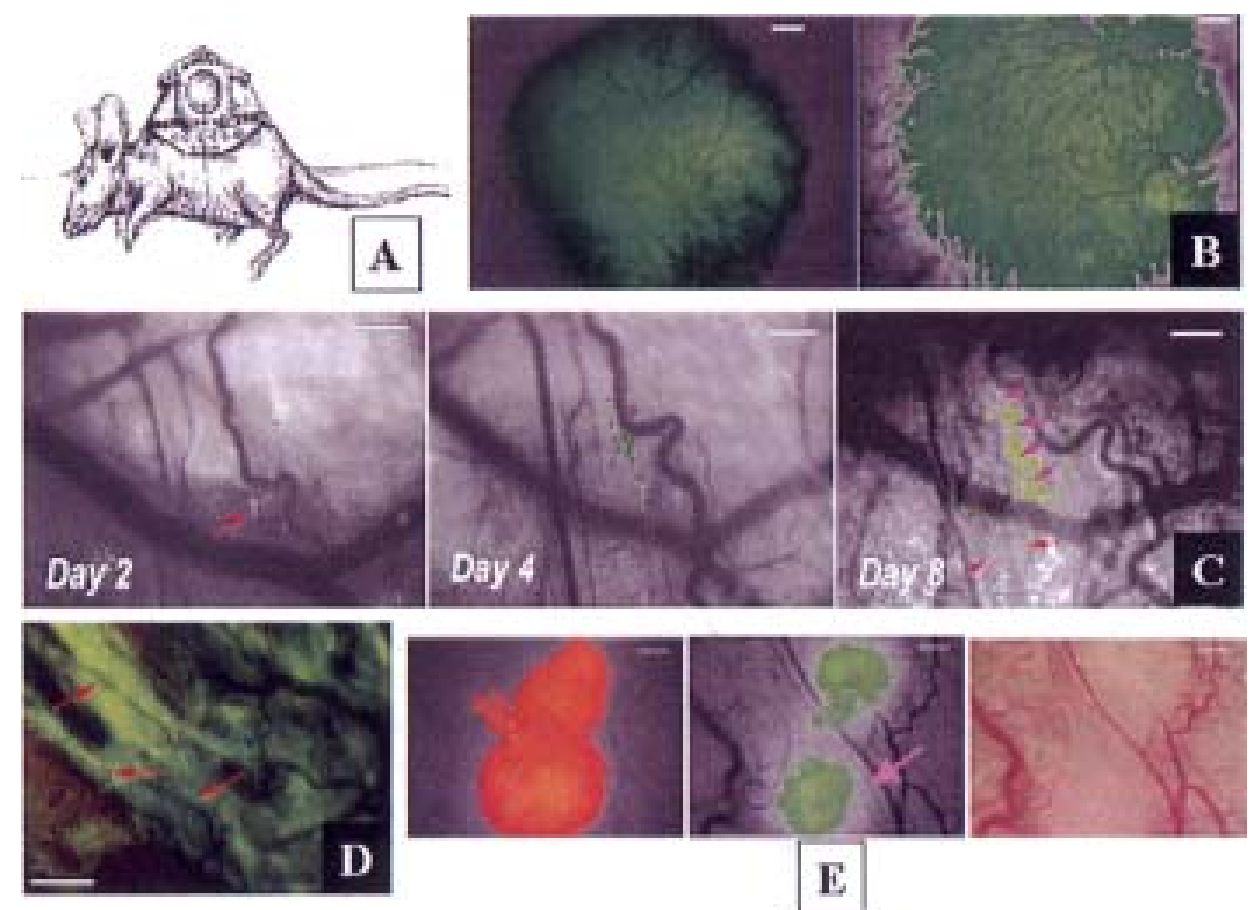

Fig. 1. Combined use of GFP and intravital microscopy for the observation of tumor growth in vivo. A. Drawing depicting window chamber implantation in the dorsal skin fold of a nude mouse. Schematic drawing of the mouse dorsal skin window chamber model.

B. Observation of tumor growth by use of cells labeled with GFP. Left panel: A tumor growing in the mammary fat pad. Note the abundance of vasculature around the edge of the tumor and the absence of vasculature toward the center of the tumor. Right panel: Same tumor line growing in the dorsal skin fold window chamber. Notice the presence of vasculature throughout the tumor surface. Bars $=300 \mu \mathrm{m}$. These images have been corrected for background autofluorescence.

C. Serial observation of tumor growth in a window chamber. About 20 cells were injected in a Balb/C mouse window chamber, and their growth was followed serially after the initial implantation. The red arrow in the Day 2 panel indicates an elongated cell. This is a typical growth pattern for this cell line and predicts for cell survival post transplant. The arrow on Day 4 points to dilated host vessels (in comparison to Day 2). The pink arrows in the Day 8 panel indicate new microvessels. The cyan arrows point to dilated vessels in normal tissue near the site of tumor growth. The size bars represent $200 \mu \mathrm{m}$. These images have been corrected for tissue autofluorescence to enhance visualization of the tumor cells. Figures are adapted from a paper published by Li et al. [61].

D. Appearance of relationship between tumor cells and angiogenic microvessels at the advancing edge of an R3230Ac mammary tumor in the skin fold window chamber model. The arrows point to selected locations of microvessels, which appear dark against a green fluorescent background of the tumor cells. The darkness comes from absorption of light by hemoglobin. Figure adapted from a paper published by Li et al. [61].

E. Appearance of skin fold window 4T1 mammary tumor containing two fluorescent reporter genes. This tumor line was transfected to stably expressed EGFP under control of a hypoxia-inducible promoter and RFP under control of a constitutive CMV promoter, prior to transplant. Left panel: Appearance of tumor using RFP filter set. Center panel: Appearance of same tumor using GFP filter set. Note that the two poles of the tumor show EGFP expression, but the center section, through which runs an arteriole (magenta arrow), does not express the reporter gene. This is expected, since the oxygen concentration is highest near the arteriole. The left and middle images are corrected for tissue autofluorescence. Right panel: Depicts appearance of this region with transillumination. Bar $=300 \mu \mathrm{m}$. (Reprinted from: G.N. Naumov, S.M. Wilson, I.C. MacDonald, E.E. Schmidt, V.L. Morris, A.C. Groom, R.M. Hoffman and A.F. Chambers, Cellular expression of green fluorescent protein, coupled with high-resolution in vivo videomicroscopy, to monitor steps in tumor metastasis, J Cell Sci 112 (1999), 1835-1842. With permission from: Oxford University Press, UK and The Company of Biologists Ltd, Cambridge, UK.)

chemiluminescent protein [24,25]. Aequorin emits its chemiluminescence at $470 \mathrm{~nm}$, which excites GFP. After an energy transfer, GFP emits its fluorescence at $508 \mathrm{~nm}$. GFP gained widespread attention after it was discovered that it can be produced heterogeneously in bacteria, yeast, and mammalian cells and emit bright green fluorescence with blue excitation light [26]. Since then, applications for GFP have been found in a wide variety of biomedical fields. The fluorescence emitted by natural GFP is weak, so intensive efforts have been made to improve the fluorescence characteristics. As a result, many variants of GFP now are available with altered biochemical and fluorescence characteristics (see Table 1 for some examples). Most of these mutations shift the excitation and emission wavelengths of the wild-type GFP. The 
Table 1

Some characteristics of the most commonly used green fluorescence protein variants

\begin{tabular}{lllll}
\hline GFP varient & Excitation/Emission $(\mathrm{nm})^{\mathrm{a}}$ & Codon optimized & Protein half-life & Fluorescence intensity $^{\mathrm{b}}$ \\
\hline GFP $(\mathrm{wt})$ & $395(470) / 509$ & none & $\mathrm{NA}$ & $1 \mathrm{x}$ \\
EGFP & $488 / 509$ & human & $>24 \mathrm{hr}$ & $35 \mathrm{x}$ \\
d1EGFP & $488 / 509$ & human & $<1 \mathrm{hr}$ & $35 \mathrm{x}$ \\
EYFP & $513 / 527$ & human & $>24 \mathrm{hr}$ & $35 \mathrm{x}$ \\
EBFP & $380 / 440$ & human & $>24 \mathrm{hr}$ & $1 \mathrm{x}$ \\
ECFP & $433(453) / 475(501)$ & human & $>24 \mathrm{hr}$ & na \\
GFPuv & $395 / 509$ & E. coli & $>24 \mathrm{hr}$ & $18 \mathrm{x}$ \\
GFPmut3.1 & $395(470) / 509$ & E. coli & $>24 \mathrm{hr}$ & $20 \mathrm{x}$ \\
\hline
\end{tabular}

${ }^{\mathrm{a}}$ In addition to the major emission maximum at $509 \mathrm{~nm}$, wtGFP, GFPuv, EGFP, and d1EGFP also have a shoulder at $540 \mathrm{~nm}$. The numbers in parenthesis represent secondary excitation/emission wavelength.

${ }^{\mathrm{b}}$ Fluorescence intensity is measured as a relative to wild-type GFP.

shifts in emission spectra are toward both shorter and longer wavelengths. For example, there are red, yellow, and blue variants available. In addition, mutations have been made that allow for more intense fluorescence and more resistance to photobleaching. Other changes have optimized protein synthesis in the host cell type. For example, an enhanced green fluorescence protein (EGFP) from the Clontech Corporation (Palo Alto, CA) was synthesized to be 35 times more fluorescent compared to the wild-type protein and is produced more efficiently in human cells. The end result is a new construct that is 350-fold more effective in comparison to the original protein [27]. Homologs from other coelenterates such as Obelia and Phialidium, both hydrozoans, and Renilla reniformis, an anthozoan, have broadened the spectrum of these proteins for visualization. STRATAGENE (La Jolla, CA) cloned and humanized the Renilla GFP. It is claimed that $R$. reniformis GFP (hrGFP) is 2.5-fold more efficient in the generation of fluorescence than the wild-type and redshifted variant of Aeqourea GFP. In addition, Renilla GFP is more stable at high and low pH and is more resistant to organic solvents or other denaturing reagents, which usually causes quenching of GFP fluorescence frozen sections. Moreover, Renilla GFP is said to be less toxic than Aeqourea GFP (STRATAGENE, http://www.stratagene.com/vol13_3/p85-87.htm). Another interesting protein was cloned from the Discosoma sp., a sea anenome relative from the Indo-Pacific sea. It absorbs ultraviolet (UV) or blue light and emits bright red fluorescence. However, its mechanism for fluorescence is not fully understood as it bears little sequence homology with the GFP family of fluorescence proteins. Its red fluorescence makes it uniquely suited for use in conjunction with members of the GFP family of fluorescent proteins in double-or triple-labeling experiments. In addition, Terskikh et al. [28] recently reported the identification of a mutant red fluorescent protein (E5 mutant from drFP583, Clontech, Palo Alto, CA). This mutant has a unique feature in that it can autocatalyze and red shift its excitation peak over time in the presence of molecular oxygen. The protein initially shows green fluorescence and gradually turns red. This property makes it useful as a molecular timer of gene transcription in cell culture or living organisms.

The extensive array of applications of the GFP proteins are possible because of the wide spectrum of cell/organism types in which they can be expressed. Furthermore, the expression results in fluorescence in targeted viable cells/organisms without any co-factors/substrates other than a requirement for oxygen [29]. For example, it has been shown that GFP and its variants can successfully be transfected and expressed in tissues of transgenic mice [30-32], Xenopus [33,34], fish [35], Drosophila melanogaster [36,37], Caenorhabditis elegans [26,38], Saccharomyces cerevisiae [39-41], E coli [26,42], bacteriophage [43], and viruses [44].

\subsection{Methods for labeling cells and proteins with green fluorescent protein}

There are many methods to label cells and proteins with GFP as it is a rather small protein $(27 \mathrm{kD})$ and has a robust three-dimensional structure that is quite resilient to external disturbances. It can be fused with many different proteins without losing fluorescence and is quite resistant to photo-bleaching (especially the redshifted mutant versions), moderate oxidizing reagents, and moderate reducing agents (2\% b-mercaptoethanol, $10 \mathrm{mM}$ DTT). It also is quite stable in the $\mathrm{pH}$ range from 7.0-11.5. It is quite sensitive to $\mathrm{pH}<7$, but intracellular $\mathrm{pH}$ values below 7 rarely are encountered, even in tumors, which often have acidic extracellular $\mathrm{pH}$ [4547]. Therefore, it has been advocated as an in vivo, non-invasive $\mathrm{pH}$ meter. It is quite stable when treated 
with mild chemical denaturants such as $1 \%$ SDS or 8 $\mathrm{M}$ urea. It also retains fluorescence after fixation with formaldehyde or glutaldehyde, a very useful property in immunohistochemical applications.

Direct transduction of the GFP gene into target cells with the GFP gene under the control of a constitutive or regulated promoter specific for the investigator's interest has been used as a method to study gene expression in vivo. For example, a 'green mouse' was made by microinjecting GFP expressing DNA fragment (with a strong, constitutively active promoter) into the pronuclei of a single-cell mouse embryo [48]. The constitutively GFP-expressing mouse can be seen as a living GFP-labeled tissue bank providing all kinds of cells, tissues, and organs for homogenous transplantation and tracing cell lineage. On the other hand, a regulated GFP-expressing transgenic mouse is an ideal model for studying the effect of spatial/temporal turn on/off status of different genes [32], the tracing of specific cell lineage [49], or effects of environmental factors on development [32]. A transgenic model was developed recently that contains GFP, under control of the e-NOS promoter (T. ten Hagen and R. de Crom, personal communication). This yields endothelial cell-specific GFP expression (Fig. 2). In some cases, GFP coding sequences have been inserted downstream of an internal ribosomal entry site (IRES), which is located $3^{\prime}$ to a gene of interest. This allows the expression of target gene to be monitored both temporally and spatially by use of the GFP expression as a surrogate marker. This approach is especially powerful when combined with the transgenic approach [50-52].

Alternatively, GFP coding sequences have been engineered into genes of interest by creating in-frame fusions with target genes. Under most circumstances, GFP-tagged proteins retain the bright green fluorescence of the GFP protein, whose presence directly reflects the expression of its fusion partner. Most importantly, such fusions usually do not change the native distribution of the fusion partner in various cellular compartments. By use of this approach, it is often possible to monitor many previously difficult-tostudy proteins in unprecedented detail because it is now possible to follow the movement of individual proteins non-invasively and continuously in a cell. This capability opened up new horizons for cell biology studies. This is especially true for fields such as membrane trafficking, a dynamic process that is difficult to study by immunofluorescence techniques [53]. It also revolutionized the study of another dynamic process, protein secretion. The use of a GFP tag allows direct tracing of the budding, transport, and fusion processes and makes it feasible to conduct time course assays [54]. For example, the nuclear export of the 60S ribosomal subunit by GFP-tagged ribosomal protein L11b (Rpl11b) has been visualized. The binding, internalization, and separation of the gonadotropin-releasing hormone receptor (GnRHR) membrane receptor and its agonist in living cells [55] recently were achieved by conjugating GFP to GnRHR. These studies are possible as long as the fusion does not affect the target gene structurally or functionally. In order to achieve this, GFP should be fused apart from the active or binding areas of the target protein to avoid interference with 3D folding and post-translational processing. Although many of these methods have been developed for studies of single cells, they are adaptable easily to in vivo studies.

Another very powerful application of the GFP family of proteins is to study protein interaction by a process called 'fluorescence energy resonance transfer (FRET)'. When two fluorescence proteins with different excitation/emission characteristics are close together, excitation of protein A will lead to emission of light with a wavelength that coincides with the excitation wavelength of protein $\mathrm{B}$, which will make protein B fluorescent. The intensity of the fluorescence from protein B should correlate with the degree of association of proteins $\mathrm{A}$ and $\mathrm{B}$. The FRET reaction has been used successfully to measure the $\mathrm{Ca}^{++}$concentration in different subcellular organelles [56], to detect apoptosis [57], to establish a protease sensor [58], and many other applications where protein-protein interactions are involved.

\subsection{Applications of green fluorescent protein in tumor biology}

\subsubsection{Tumor cell biology}

At the cellular level, the GFP proteins have greatly facilitated our understanding of tumor cell structures and signaling pathways. Many of the signal transduction proteins now have been examined in exquisite detail with the help of the fluorescent proteins.

An important question in cancer research is how to distinguish apoptosis from necrosis. DNA staining and the terminal deoxynucleotidyl transferasemediated dUTP nick-end-labeling (TUNEL) assay are established methods to show apoptosis, but they require removal of the tissue to conduct the assay. One solution is to observe the fluorescence distribution of a GFP-tagged nuclear pore membrane protein. A neuroblastoma cell line was established that expresses a 


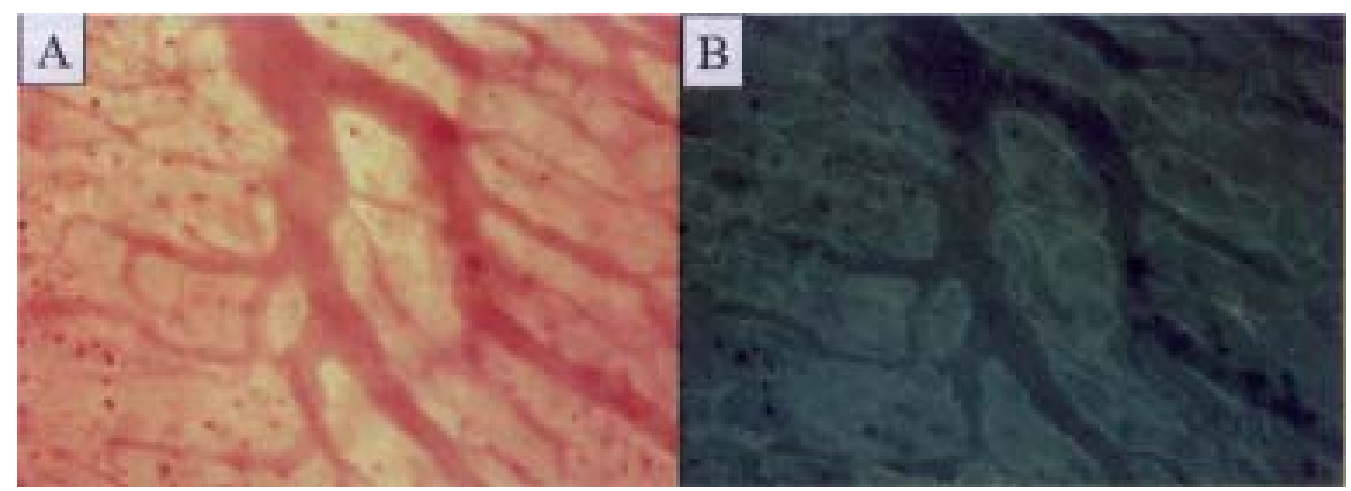

Fig. 2. Appearance of tumor microvessels in B16 melanoma grown in a mouse skin fold window chamber. A. Appearance of selected tumor region using transillumination. B. Appearance of same region, as imaged using epifluorescence. The specific expression of GFP in endothelial cells is visible readily. The small green spots seen in the larger vessels represent accumulation of GFP in Golgi bodies. This unpublished figure was kindly supplied by Drs. Timo L.M. ten Hagen and R. de Crom, Departments of Surgical Oncology and Cell Biology, Erasmus Medical College, Rotterdam, The Netherlands.

GFP-POM121 (a nuclear pore membrane protein) fusion protein [59]. This construct diminished or lost its fluorescence in apoptotic cells but was unaffected in necrotic cells. Another example involves the evaluation of the activity and function p53, an important tumor suppressor gene. Zhang et al. engineered a GFP reporter containing $\mathrm{p} 53$ responsive sequences to monitor wild-type p53 activity [60].

\subsubsection{Tumor angiogenesis and physiology}

Although there have been numerous studies of tumor development in vivo, there is limited understanding of tumor physiology at the cellular level. The main reason is the lack of methods to follow tumor cells noninvasively, in a manner similar to in vitro studies. The application of GFP promises to change the situation considerably.

\subsubsection{Angiogenesis}

Angiogenesis is key to tumor growth and metastasis. It now is well established that angiogenesis is essential for tumor growth and development. It is involved intimately with tumor invasion and metastasis. However, it has been difficult to study the early stages of tumor angiogenesis because there has been no tool to visualize endothelial cells in vivo non-invasively. Most previous studies relied on immunohistological methods that characterize blood vessels by use of antibodies that specifically stain for endothelial cells. However, this approach allows only for angiogenesis to be observed when the tumor tissues are fixed, thereby precluding serial measurement. Knowledge of the molecular mechanisms at these early stages of angiogenesis may provide important clues regarding how tumor angiogenesis is initiated. The availability of GFP has significantly boosted studies in this area. For example, tumor angiogenesis at the earliest stages of tumor growth was observed serially and non-invasively in a rodent dorsal skinfold chamber. GFP-labeled tumor cells were observed in rodent dorsal skin window chamber models non-invasively and serially up to four weeks after transplantation of 20-50 cells [61]. The results provided new insights into the complex interplay between tumor cells and host vasculature at these earliest stages of tumor growth. Four stages of early angiogenesis were seen to occur: (1) The initial orchestration of tumor angiogenesis involved migration of tumor cells toward pre-existing vasculature before neovascularization (Fig. 1(C)); (2) Changes in surrounding microvessel structure, such as vasodilation and increased tortuosity, were seen at the 60-80 cell stage; (3) Clear demonstration of new vessel formation was seen at the 100-300 cell stage; and (4) Both tumor lines developed intimate contact with developing neovasculature as the tumor continued to expand into surrounding normal tissue (Fig. 1(D)). These results clearly demonstrated the power of GFP in facilitating non-invasive, cellular level studies of tumor angiogenesis with high spatial resolution.

Another example of the use of GFP in the study of tumor angiogenesis was conducted by Fukumura and colleagues. Tumor growth was monitored in skin-fold window chambers of a transgenic mouse strain that has the GFP gene under control of the promoter for the vascular endothelial growth factor (VEGF) gene. This study demonstrated that stromal cells play a predominant role in VEGF generation [62]. A transgenic mouse with the Tie 2 gene promoter controlling the EGFP gene 
was reported by Sato and colleagues [63]. The Tie2 gene is expressed exclusively in endothelial cells; thus this type of mouse expresses GFR only in endothelial cells. The availability of this mouse strain clearly will facilitate the study of angiogenesis by making available large quantities of endothelial cells that easily can be sorted by fluorescence-activated cell sorting (FACS).

\subsubsection{Hypoxia}

It is well established that hypoxia plays an important role in the regulation of angiogenesis. Recently, we created doubly transfected cell lines that contain GFP under control of a hypoxia-inducible promoter (HIF-1 responsive) and red fluorescence protein (RFP) under control of a constitutive promoter. Using this combination, we were able to compare the distribution of all tumor cells with those regions that have HIF-1 upregulation (Fig. 1(E); Dewhirst, Cao, Li, Moeller, unpublished data). Using tumor cells that express GFP under control of the VEGF promoter, others have examined the relationship between oxygenation, extracellular $\mathrm{pH}$, and VEGF expression patterns $[64,65]$.

\subsubsection{3. $p H$}

The protonation or deprotonation state of the chromophore of GFP is $\mathrm{pH}$ sensitive and can cause the shift of its excitation and emission spectral properties. The fluorescent intensity of GFP also can be affected by $\mathrm{pH}$. This property has been used by a number of groups to measure intracellular $\mathrm{pH}$ non-invasively. Acidic $\mathrm{pH}$ is a common property of many tumors. Thus, GFP could be informative in in vivo studies. Because heterologously synthesized GFP has no specific preference to intracellular organization, it is possible to target GFP to various subcellular organelles in a cell, thereby studying proteins in those organelles. In one study, investigators engineered GFP with various targeting peptide sequences toward different organelles [66]. By pH titration and GFP quenching experiments plus in vivo $\mathrm{pH}$ calibration, they measured subcellular $\mathrm{pH}$ values in different organelles such as mitochondria, Golgi body, and endoplasmic reticulum. This method of measuring subcellular $\mathrm{pH}$ is less toxic than chemical $\mathrm{pH}$ tracers and can allow serial $\mathrm{pH}$ measurements. This method has not been attempted in vivo to the reviewers' knowledge.

\subsubsection{Micrometastasis}

Invasion and metastasis are key steps in tumor development. However, early stage invasion and micrometastases are difficult to study. Tumor cell migration studies were studied historically with fluorescent dye-labeled tumor cells. However, the fluorescent dye approach only can study tumor cell migration for a few hours. Alternatively, radio-labelled tumor cells have been used to monitor the arrest of tumor cells in the lung. This method does not allow for examination of metastasis at the cellular level. GFP provides a new way to carry out experiments examining metastasis. With GFP-transduced tumor cells, morphological changes such as polarization, cellular mobility in stroma, tumor cell distribution around blood vessels, and time course of extravasation all can be observed non-invasively. By labeling different tumor cells with GFP [67], it is possible to compare highly metastatic and poorly metastatic tumor cell lines [12]. Hoffman and colleagues pioneered the use of GFP-expressing tumor cells for serial whole-body imaging of metastasis in mice without the need for window chambers. The resolution of this system is remarkable, with observation of single cells being possible in some circumstances [1,68-76].

GFP has facilitated discovery of surprising results in metastasis research. For example, it once was believed that metastasis engraftment required extravasation at distal sites. Al-Mehdi et al. reported that GFP-labeled transformed rat embryonic fibroblast and human fibrosarcoma cell lines establish metastases in the lung following intravenous (IV) injection by attachment to pre-capillary arterioles [77]. They clearly demonstrated that this was not due to trapping, since the vessels were larger than the diameter of the attached cells (Fig. 3(A)). Cells proliferated selectively inside vessels up to a size beyond which the vessel appeared to burst from the pressure of the proliferating cell mass. This observation challenges the paradigm that hematogenous metastases mainly are formed from tumor cells trapped in capillaries and that growth can occur only when cells have escaped from the vasculature. Recently, this same group demonstrated that intravascular tumor proliferation also occurs in spontaneous lung metastases of a tumor line that is highly invasive locally [78].

Similar studies examining the biology of liver metastasis growth have shown the more traditional scenario of tumor cell adhesion to microvessels, extravasation, engraftment, and angiogenesis formation. Some extravasated tumor cells also have been found to remain dormant in liver parenchyma for long periods of time [12] (Fig. 3(B)). 


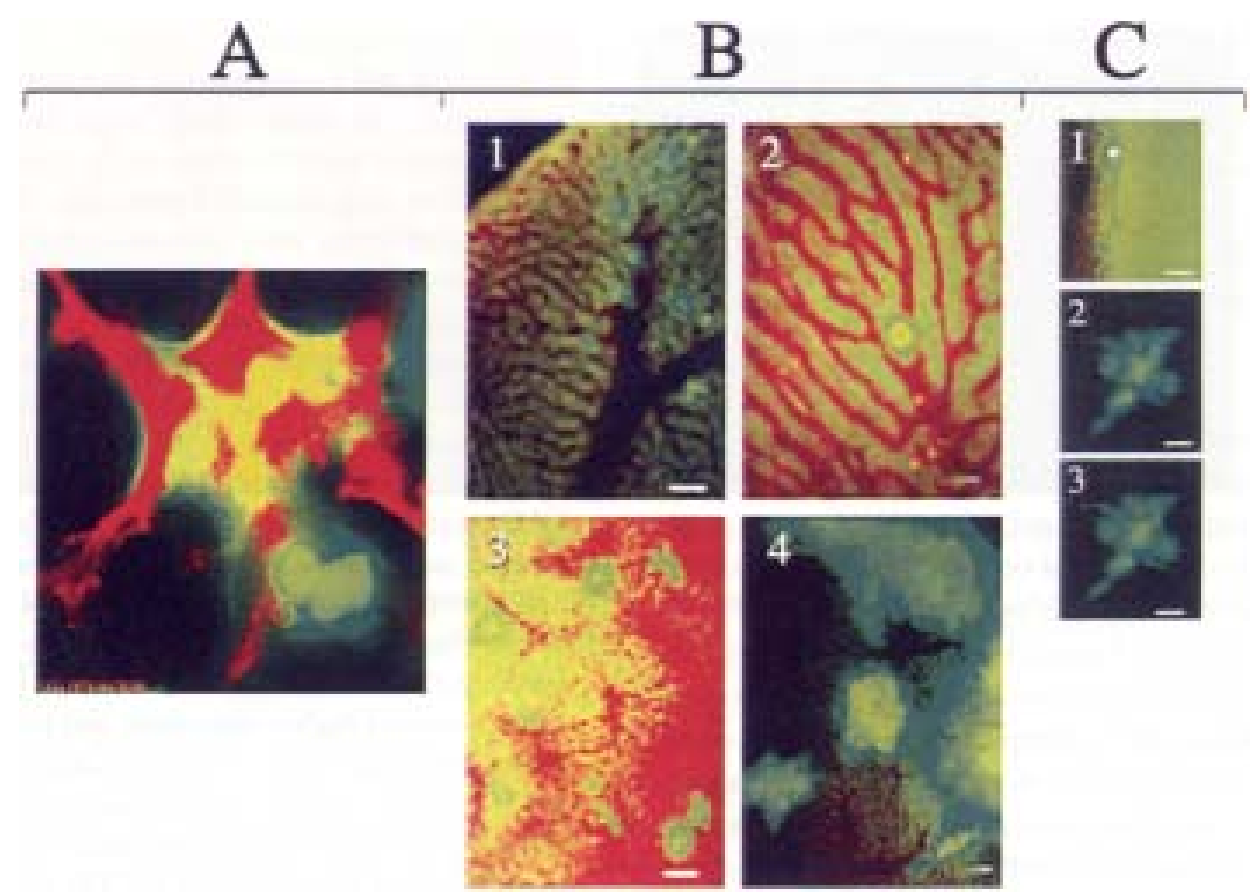

Fig. 3. A. Image of an intravascular lung tumor colony (green cells) from a rat fibrosarcoma cell line stably transfected with GFP. The endothelium is imaged using DiI (1, $1^{\prime}$ - dioctadecyl-3,3,3', $3^{\prime}$-tetramethyl-indocarbo-cyanine perchlorate)-labelled LDL (low density lipoprotein; red color), which is preferentially taken up by vascular endothelial cells (Muschel et al., unpublished data). The tumor cells, which spontaneously metastasized into the lung, were visualized by high-resolution digital video microscopy as described Wong et al. [78]. This unpublished figure was kindly supplied by Dr. Ruth Muschel.

B. Sequential steps of metastasis in mouse liver, visualized in vivo by intravascular videomicroscopy (IVVM) of GFP-expressing CHO-K1 cells. 1. Intravascular cells arrested due to size restriction within mouse liver sinusoids near terminal portal venules (acinar zone 1), visualized one hour after injection. Tumor cells appear bright green against the background of dark red blood vessels and pale yellow autofluorescence of the liver tissue. Bar $=50 \mu \mathrm{m}$. 2. Extravasated cell observed 24 hours after injection, located out in liver tissue between sinusoids. By IVVM it could be seen that blood flow had resumed within these sinusoids. Bar $=25 \mu \mathrm{m}$. 3. Overview showing small micrometastases four days after cell injection. Note the variety of shapes and sizes, as well as pseudopodial projections at the periphery of most micrometastases. Bar $=100 \mu \mathrm{m}$. 4 . Larger micrometastases separated by normal tissue are present at day nine, many of which exhibit pseudopodial projections extending from their periphery into the surrounding tissue. Bar $=100 \mu \mathrm{m}$. Views $1-4$ all are photomicrographs taken with a $35 \mathrm{~mm}$ camera, using epifluorescence plus a low level of transillumination.

C. Morphological observations by IVVM: interactions of cells and metastases with liver microenvironment. 1. An extravasated CHO-K1-GFP cell at day one, in the process of migration to the hepatocyte layer in the subcapsular region. Cell body (*), slightly below the plane of focus, extends a long, bifurcated pseudopodial projection up toward the liver surface. (Viewed by epifluorescence plus transillumination.) Bar $=25 \mu \mathrm{m}$. 2, 3. Micrometastasis at day four observed by epifluorescence alone, at two different focal depths (optical slicing). 2. Viewed at a deeper plane of focus, center of micrometastasis is sharply defined, but peripheral cells appear out of focus. Bar $=25 \mu \mathrm{m}$. 3 . Viewed nearer to the liver surface, peripheral cells are defined more sharply than are cells at the center, which indicates that the peripheral cells had invaded the hepatocyte layer located just below the liver capsule. Bar $=25 \mu \mathrm{m}$. Views are photomicrographs taken with a $35 \mathrm{~mm}$ camera. Figures 2(B) and (C) are reproduced from a paper by Naumov et al. [12], with permission of the author and publisher.

\subsubsection{Cancer gene therapy}

Gene therapy is a relatively new field in cancer research. With the completion of the human genome and rapid advances in genomics, there are a large number of candidate genes suitable to be tested in cancer gene therapy studies. One of the biggest hurdles in cancer gene therapy is effective delivery of therapeutic genes to tumor cells. This is an important issue to cancer therapy because virtually all gene therapy vectors are bigger than traditional chemotherapeutic drugs. Various strategies have been used to make gene therapy tumor- cell specific. One of the tools that should be very useful in facilitating the creation of more effective tumorcell targeting gene therapy vectors is an approach that allows the non-invasive, dynamic monitoring of gene transduction in vivo by various gene therapy vectors. Again, GFP is an ideal tool in this case. By use of a dorsal skinfold window chamber, we were able to monitor the activity of adenovirus in infecting a mammary cell carcinoma non-invasively over the course of days [79]. In addition, long-term, non-invasive monitoring of gene 
expression has been achieved in the retina [80] and in the brochial epithelium [81].

\subsubsection{Limitations of GFP as a reporter gene}

There are two primary limitations to the use of this reporter gene. It can be toxic to cells if they produce large amounts of the protein, and this can inhibit tumor growth or alter the behavior of a tumor line. For example, we recently determined that 4T1 mammary tumor cells that express the highest levels of RFP after retroviral transfection lose their invasive characteristics, grow slower than the wild-type line when transplanted subcutaneously or orthotopically, and lose their ability to metastasize (Dewhirst and Moeller, unpublished observations). Sometimes it is better to select clones that show intermediate levels of expression in order to minimize this effect. Also, it sometimes is difficult to establish stably tranfected cell lines. This is important because loss of GFP signal could be misinterpreted as reduction in cell number in such cases. In addition, even in cell lines that show stable expression in vitro, there may be loss of expression in vivo over time. We experienced this with the R3230Ac tumor line that was stably transfected with GFP under the cytomegalovirus (CMV) promoter. While this tumor line maintained stable expression over many generations in vitro, it was unstable in vivo. In this case, we were able to use the instability in expression to study the phenomenon of genetic instability, so the behavior in this instance became an advantage [82]. In summary, GFP already has been used in a wide variety of biological research fields. It can be expected that the list of its applications will continue to grow in the foreseeable future, but care should be taken to minimize sources of artifact.

\section{Study of vascular permeability and interstitial solute transport}

Various methods have been developed for quantitative investigation of transvascular and interstitial transport of solutes in tumor tissues. Most of these methods are based on intravital fluorescence microscopy and transparent window chamber models of tumors. One exception is the radio-imaging technique, which is based on determination of radioactivity distribution in a tumor tissue section at a specific time point after administration of radio-labeled solutes $[83,84]$. The advantage of the radio-imaging technique is that it can be used to study interstitial transport in any tissue. However, this technique is limited by an assumption that interstitial diffusion is only in the direction that is parallel to the plane of tissue section; i.e., diffusion in the perpendicular direction is negligible. When the tumor section is not parallel to the direction of diffusion, the radio-imaging technique underestimates the rate of diffusion and, thus, the diffusion coefficient of solutes in tumors. Other imaging techniques used in nuclear medicine (e.g., magnetic resonance imaging (MRI) and positron emission tomography (PET) also may be used in transport studies if they can be further improved in terms of spatial resolution, in vivo calibration of signal intensity versus solute concentration, and/or solute labeling with contrast agents.

Most data of vascular permeability and interstitial transport parameters in tumors are obtained based on techniques that involve intravital fluorescence microscopy and transparent window chamber models of tumors. The common procedures depend on measuring fluorescence intensity in tumor tissues as a function of time after fluorescently labeled solutes are administered and analyzing the intensity profiles, using different mathematical models, to determine the transport parameters of solutes [19,85-93].

Methods for vascular permeability measurement can be divided into four categories. Methods in the first category were developed for non-invasive measurement of vascular permeability in thick tumor tissues grown in transparent window chambers $[19,85,86]$. In these methods, the average fluorescence intensity in a region of interest in tumor tissues first is measured with a photomultiplier tube or a video camera at various time points after intravenous injection of fluorescently labeled solutes. The rate of intensity increase is a linear function of the average permeability of tumor vessels in that region. The two constants in the linear function depend on the ratio of vascular surface area versus vascular volume $(\mathrm{S} / \mathrm{V})$ in that region, the rate of plasma clearance of solutes, and microvascular hematocrit. In most studies, the microvascular hematocrit is assumed to be $19 \%$ [94], and the rate of plasma clearance is determined through direct sampling of the blood in systemic circulation at different time points after solute injection. To determine $\mathrm{S} / \mathrm{V}$, these methods have to assume that the probability functions of diameter and length of microvessels observed in tumor tissues under the glass window of the chamber are the same as those in the deeper layers of tumor tissues in which the average fluorescence intensity is determined. This assumption, which is valid only when the diameter and length distributions are completely random and the sample size is large, may introduce some error in vascular perme- 
ability measurement. In addition, care must be taken during the experiment to minimize photobleaching of fluorescent markers. Photobleaching may cause an underestimation of the vascular permeability.

If the total thickness of tumor tissues is less than $40 \mu \mathrm{m}$, such as the tumor grown in the rabbit ear chamber, solute transport in tumors can be assumed to be two dimensional. In this case, the concentration of a fluorescently labeled solute can be monitored directly and non-invasively as a function of time in the plasma layer of blood within the microvessel and immediately outside the vessel wall, respectively, under an intravital fluorescence microscope. These concentration profiles are used to determine the rate of plasma clearance and the permeability of solutes in individual tumor vessels [87].

The third method for permeability measurement involves cannulation of individual microvessels with a glass micropipette and perfusion of these vessels with fluorescently labeled compounds [88]. This is similar to the classic method for permeability coefficient measurement in normal tissues [95-97] but is technically challenging and particularly difficult to do in tumors because of the fragility of microvessels [88].

The fourth method is based on confocal or multiphoton fluorescence microscopy $[3,98,99]$. In this method, the distribution of fluorescence intensity in a plane perpendicular to the axis of a microvessel is determined as a function of time after intravenous injection of fluorescently labeled solutes. The intensity profiles are used to calculate the permeability coefficient of solutes in that vessel, assuming that the permeability is uniform along the vessel and there is no transport of solutes into the plane from other regions of the tissue. This assumption often is invalid in solid tumors, since tumor vascular permeability is heterogeneous. To overcome the heterogeneity problem, serial optical sections need to be taken along the vessel, and the method of data analysis must be modified accordingly. However, the confocal or multiphoton fluorescence microscopy method cannot be used in tissues with high vascular density because solutes extravasated from other vessels may enter the plane before the permeability measurement is finished.

Based on the same chamber models and microscopy techniques as those discussed above for vascular permeability measurement, several methods have been developed for quantification of interstitial transport of solutes. One such method is the Fluorescence Recovery After Photobleaching (FRAP) technique, which was developed initially for the analysis of receptor mobil- ity in the plasma membrane of cells [100]. It was then adopted by Chary and Jain for quantitative measurement of diffusion and convection of solutes in thin preparation of tumor tissues [90] and later improved by Berk et al. for determining solute transport in thick tissues $[89,93]$. The experimental procedures in the FRAP technique include: local administration of fluorescently labeled solutes into tumor tissues grown in transparent window chambers, photobleaching of the fluorescence in a small region of tumor via a strong laser beam after the concentration distribution becomes uniform, and monitoring of fluorescence recovery in the bleached area via a photomultiplier tube or a video camera. The rate of recovery depends on the diffusion coefficient and binding affinity of solutes to tissue structures. Thus, the FRAP technique can be used to determine two of these parameters [89,90,93]. In addition to the rate of fluorescence recovery, the bleached area also may move in tissues due to convective transport. The velocity of movement is equal to the convective velocity of solutes. Thus, the FRAP technique also has been used to determine the convective velocity [90].

Another method for determining the interstitial transport of solutes is the relaxation technique [91,101]. It is based on thin tissue preparations in transparent window chamber models (e.g., the rabbit ear chamber). In this case, solute transport can be considered as onedimensional in the direction perpendicular to the vessel. To determine the diffusion coefficient in tumor tissues, the distribution of fluorescence intensity around individual tumor vessels first is quantified after intravenous injection of fluorescently labeled solutes. The diffusion coefficient of solutes then is determined through curve-fitting the intensity profile by a theoretical curve from the transient and one-dimensional diffusion equation. If the tumor preparation is not thin or the diffusion is not one-dimensional, confocal or multiphoton fluorescence microscopy technique will be used to determine the three-dimensional distribution of fluorescence intensity around individual vessels at different time points $[3,99]$; and the diffusion coefficient of solutes will be determined through curve-fitting the intensity profile by a theoretical prediction from the transient and three-dimensional diffusion equation.

Studies based on transparent window chamber preparations are of fundamental importance in understanding mechanisms of molecular transport in tumor tissues. It has been found that macromolecular transport is hindered in tumors and that microvascular permeability depends upon the site of tumor growth and endogenous levels of nitric oxide production [3,19,102,103]. 
The intravital fluorescence microscopy techniques also have been important for the study of liposome delivery in tumors. By using liposomes of various diameters, investigators are able to examine the size of pores in tumor microvessels and observe that the cutoff size ranges from $<1 \mathrm{~nm}$ to $\sim 2 \mu \mathrm{m}$ among different tumors [19,104-106]. In other studies, it has been determined that hyperthermia changes microvessel pore cutoff size and that such effects can occur at temperatures as low as $40^{\circ} \mathrm{C}[104,107]$. Window chambers also have been used to examine the effects of hyperthermia on the delivery of fluorescently labeled peptide polymers in tumors [108] (Fig. 4). These polymers demonstrate a unique property of inverse phase transition, which occurs at a defined temperature that is polymer specific. The phase change makes the polymer become hydrophobic and precipitate.

\section{Oxygen transport: Red cell flux and microvascular hematocrit}

The flux of red cells in the microcirculation is of fundamental importance in the control of oxygen transport. Microvascular hematocrits have been measured in one tumor line by fluorescently labeling red cells from a donor animal ex vivo and then injecting the cells IV into a recipient animal that has a window chamber. Red cell flux is determined by first measuring the number of labeled cells that pass a particular point in a microvessel as a function of time. Correction back to total cell flux is done by determining the fraction of labeled red cells in the peripheral circulation using flow cytometry and dividing that fraction into the measured red cell flux. Microvascular hematocrit is determined by using a mathematical formula that includes the red cell volume, flow velocity, red cell flux and the dimensions of the microvessel in which the flux was measured. One limitation of this method is the inability to determine the dimensions of the microvessels under fluorescent illumination when the only objects visible are the fluorescent red cells. One way to mitigate this problem is to observe the vessel of interest using transmission imaging, but this requires changing back and forth between transmission and fluorescence imaging. A significant improvement was achieved when fluorescently labeled liposomes were added simultaneously with the red cells. The liposomes served as a blood pool agent that was easily observable simultaneously with the red cells. Several applications of this method have been reported. For example, average microvascular hemat- ocrits were reported to be similar in tumor vs. normal tissue, but there was a wider distribution of values in tumor tissues. Red cell fluxes averaged two-fold higher in tumors, but again had higher variability [94]. The wider range of variation in these parameters included a significant proportion of tumor microvessels with zero or near zero red cell flux/hematocrit. These types of microvessels, which could represent up to $10 \%$ of all vessels in tumors, thus represented a previously unrecognized source of hypoxia [109]. The same method was used to show a relationship between changes in red cell flux and microvascular oxygenation [110]. This report was key in understanding intermittent hypoxia in tumors because it clearly demonstrated that this form of tumor hypoxia does not require total vascular stasis. Secondly, the instability in flow was a relatively ubiquitous phenomenon, suggesting that intermittent hypoxia may be much more common than previously recognized.

There are limitations to these methods. First, labeling of red cell membranes with a fluorescent dye can change the viscosity of the cell, thereby altering its behavior in the microcirculation. The method developed by Unthank et al., which uses carbocyanine to label the red cell membrane, yields very little artifact of this type [111]. Second, the presence of hemoglobin in red cells absorbs fluorescent light. This limits the size of vessels that can be studied in this manner to something less than $50 \mu \mathrm{m}$ in diameter. Third, flow velocities that exceed about $1.5 \mathrm{~mm} / \mathrm{sec}$ cannot be measured because of the framing rate that is used for most cameras. Fortunately, red cell velocities in most tumor microvessels less than $50 \mu \mathrm{m}$ diameter have flow velocities lower than $1.5 \mathrm{~mm} / \mathrm{sec}$. Finally, accurate measurement of red cell flux requires counting at least 100 cells, since the standard deviation of this type of measurement is equal to the square root of the mean. Vessels with relatively low red cell flux may not be measured easily with this method. This can be addressed partially if more labeled red cells are added, but there are limitations to this. If the proportion of labeled red cells is too high, the cells will overlap with each other; thereby making accurate counting difficult, particularly in higher flux vessels.

\subsection{Tumor oxygenation and extracellular $p H$}

Jain and co-workers modified a well-established method for measuring intracellular $\mathrm{pH}$ (fluorescence ratio method) to measure the interstitial $\mathrm{pH}$ of tumor tissues [112,113]. This method is based on administration of a dye that freely diffuses in the interstitial space. 

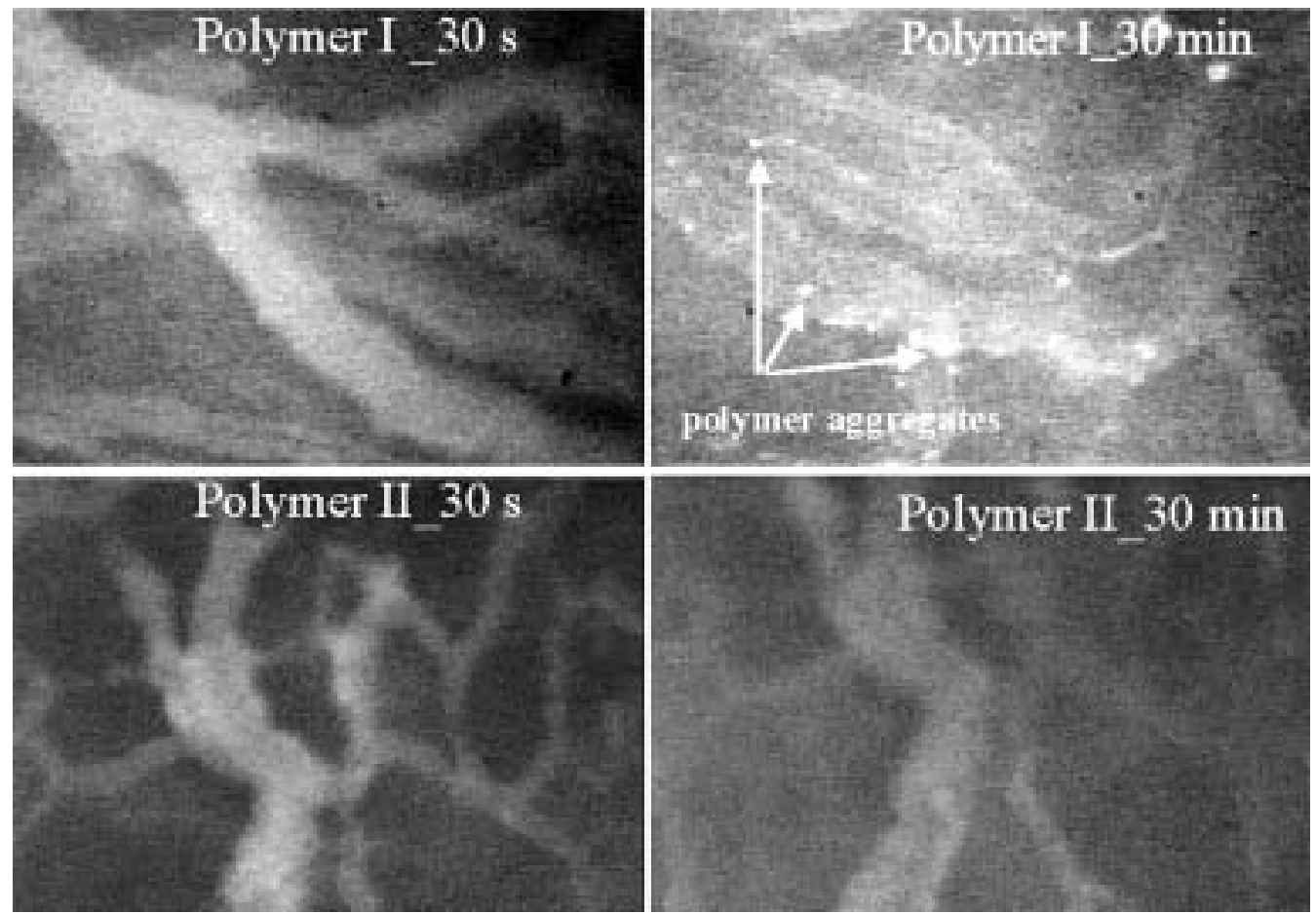

Fig. 4. Appearance of fluorescently labelled polymers as a function of time post-IV injection in a skin fold window chamber containing a human ovarian carcinoma xenograft (SKOV3). The window chamber is being heated to $42^{\circ} \mathrm{C}$ while polymer extravasation is monitored. Upper left: Appearance $30 \mathrm{~s}$ after polymer injection, highlighting tumor microvessels. Upper right: Appearance of same tumor region after 30 min. There is clear extravasation of contents from the vessels, as the interstitial space shows higher fluorescence intensity. In addition, the polymer is shown to undergo an inverse phase transition, leading to temperature-dependent hydrophobic collapse and formation of visible particles of polymer in the tissue. Some aggregates are indicated by arrows. The lower two panels show a control polymer that does not undergo the phase transition in this temperature range. These data are similar to those reported already for this class of drug carrier [108] and were kindly provided by Drs. Wenge Liu and Ashtosh Chilkoti.

When this dye is epi-illminated, it fluoresces with a characteristic wavelength distribution. The wavelength distribution is dependent upon the $\mathrm{pH}$, however. The key to measuring $\mathrm{pH}$ is to choose one wavelength to make the measurement that is not affected by $\mathrm{pH}$ and another that has a well-characterized $\mathrm{pH}$ dependence. The ratio of fluorescence intensities at these two wavelengths, therefore, can be related back to the $\mathrm{pH}$ of the dye. The investigators used this method to show that there are discernable $\mathrm{pH}$ gradients that exist at the microregional level, much in the same way that oxygen gradients are seen between microvessels. When oxygen profiles were compared with $\mathrm{pH}$ gradients, however, there was no consistent relationship [114].

A reliable method for measuring tumor oxygenation using a fluorescent method has not been identified as yet. However, the phosphorescence lifetime imaging method has proven very useful for window chamber studies. The basis for this measurement relies on phosphorescence that is emitted from a metal porphyrin complex after being illuminated with visible light [115-
119]. The decay time for the phosphorescence is oxygen dependent, which forms the basis for the measurement [120]. Typically, the dye is administered intravenously and allowed to circulate before the tissue is illuminated for the measurement. This measurement requires sophisticated image analysis software and hardware as well as a flash lamp; but it has the advantage that the signal-to-noise ratio is inversely proportional to $\mathrm{pO} 2$, so the accuracy is best at lower oxygenation values, which are typical in tumors. The method has yielded powerful data regarding tumor tissue oxygenation. As mentioned above, it has been possible to use the method to compare $\mathrm{pH}$ gradients with oxygen gradients in tumors. Recently, oxygenation maps obtained with this method have been compared to expression patterns for VEGF expression, using a GFP reporter, driven by the VEGF promoter [65]. Dewhirst and colleagues have used the method to establish the presence of longitudinal oxygen gradients in tumors - a feature of tumor oxygen transport that previously was not rec- 

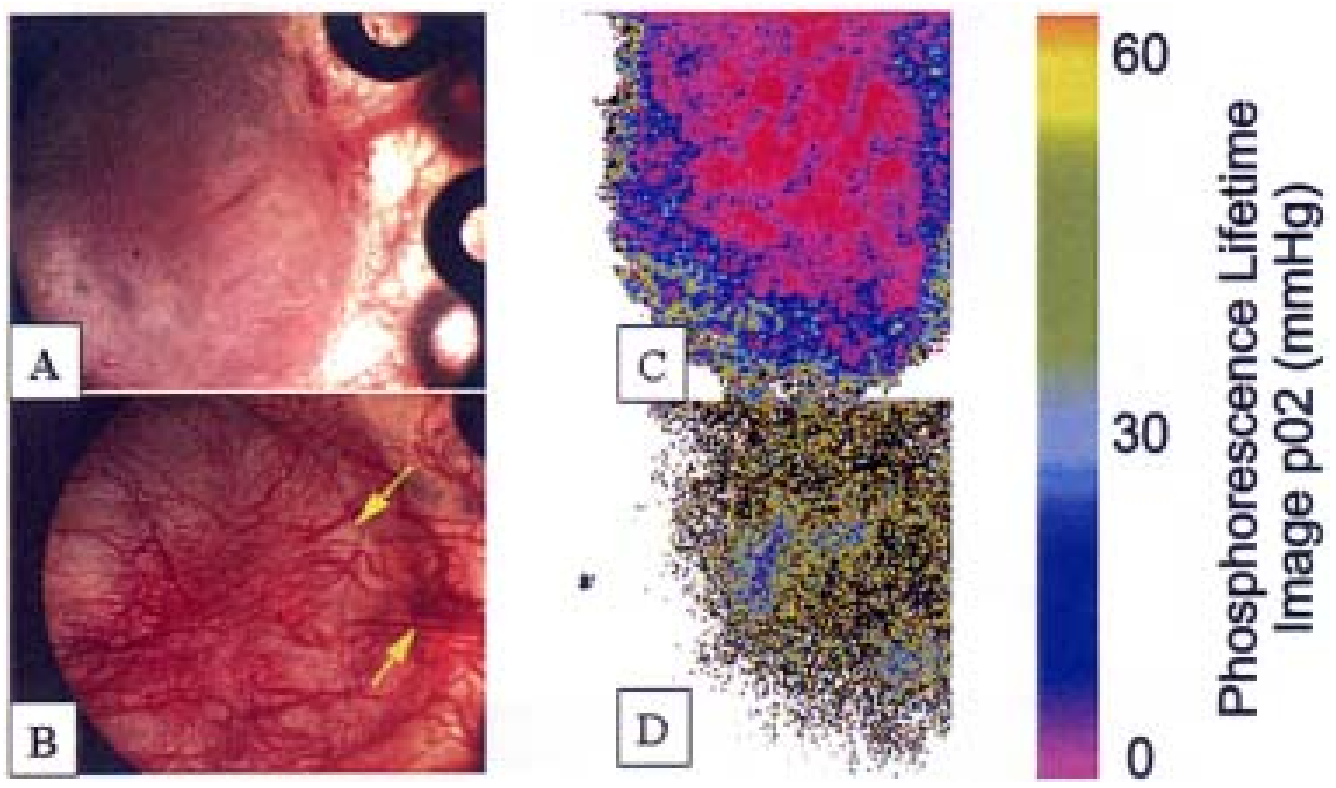

Fig. 5. Microscopic view of both surfaces of window chamber tumor preparations in a rat, as visualized by transillumination and phosphorescence lifetime imaging. In this type of preparation, the epidermis is removed from both surfaces of the flap, leaving a fascial plane upon which a tumor is transplanted. The tumor grows on the surface of the fascia, deriving its vascular supply from pre-existing fascial post-capillary venules and arterioles (A). The tumor surface has much lower vascular density than the fascial surface (B), and is devoid of arterioles. C/D. Phosphorescence lifetime imaging shows heterogeneity of oxygenation within each surface. Overall, the tumor surface (C) is much more hypoxic than is the fascial surface (D). These unpublished data are similar to previously published studies using this method [120] and are provided by the author (MWD).

ognized as being important for development of tumor hypoxia [120] (Fig. 5).

\section{Leukocyte-endothelial cell interactions}

A simple method for following the intravascular behavior of leukocytes is to inject a small quantity of fluorescent dye such as acridine orange or sulforhodamine, IV. These water-soluble dyes will stain the DNA of circulating leukocytes, which can then be visualized in the microcirculation using epifluorescence. This method has been used extensively in normal tissue preparations to examine the interactions between leukocytes and endothelial cells under inflammatory conditions [121,122]. Jain and colleagues first used this method in the rabbit ear chamber to examine the behavior of natural killer (NK) cells and other leukocytes in tumor and normal microcirculation [123,124]. They found that rolling and adherence of these cells to tumor vascular endothelium was augmented by cytokines such as interleukin 2 (IL2). However, as an aside, they also noticed that, in general, leukocyteendothelial cell interactions were depressed in tumor microvessels as opposed to normal vessels. Dewhirst et al. found that exogenous administration of the vasoac- tive and pro-inflammatory peptide, bradykinin, was ineffective in increasing leukocyte-endothelial cell interactions in tumor microvessels, but it potently increased these interactions in normal tissues of skin-fold window chambers [125]. Wu examined this phenomenon further to demonstrate that the depression of leukocyteendothelial cell interactions could not be upregulated by a variety of inflammatory cytokines, including the chemotactic peptide formylmethionylleucylphenylalanine (fMLP), bradykinin, or TNF $\alpha$ (Fig. 6). It was demonstrated later that although radiation exposure was effective in increasing leukocyte-endothelial cell interactions in normal tissues, it resulted in further reduction of these interactions in tumors [126].

A significant number of additional papers have been published that point to some of the mechanisms involved in the reduced capacity of tumor microvessels to support leukocyte interactions. It is known that key adhesion molecules are downregulated as a result of increased expression of proangiogenic molecules such as VEGF [127-129]. Nitric oxide, which often is produced by tumor cells in elevated amounts, also is involved in the downregulation [102]. In most studies, the comparator with tumor has been subcutaneous tissues of the skin-fold window chamber. Melder et al., however, showed that normal brain microvessels were 


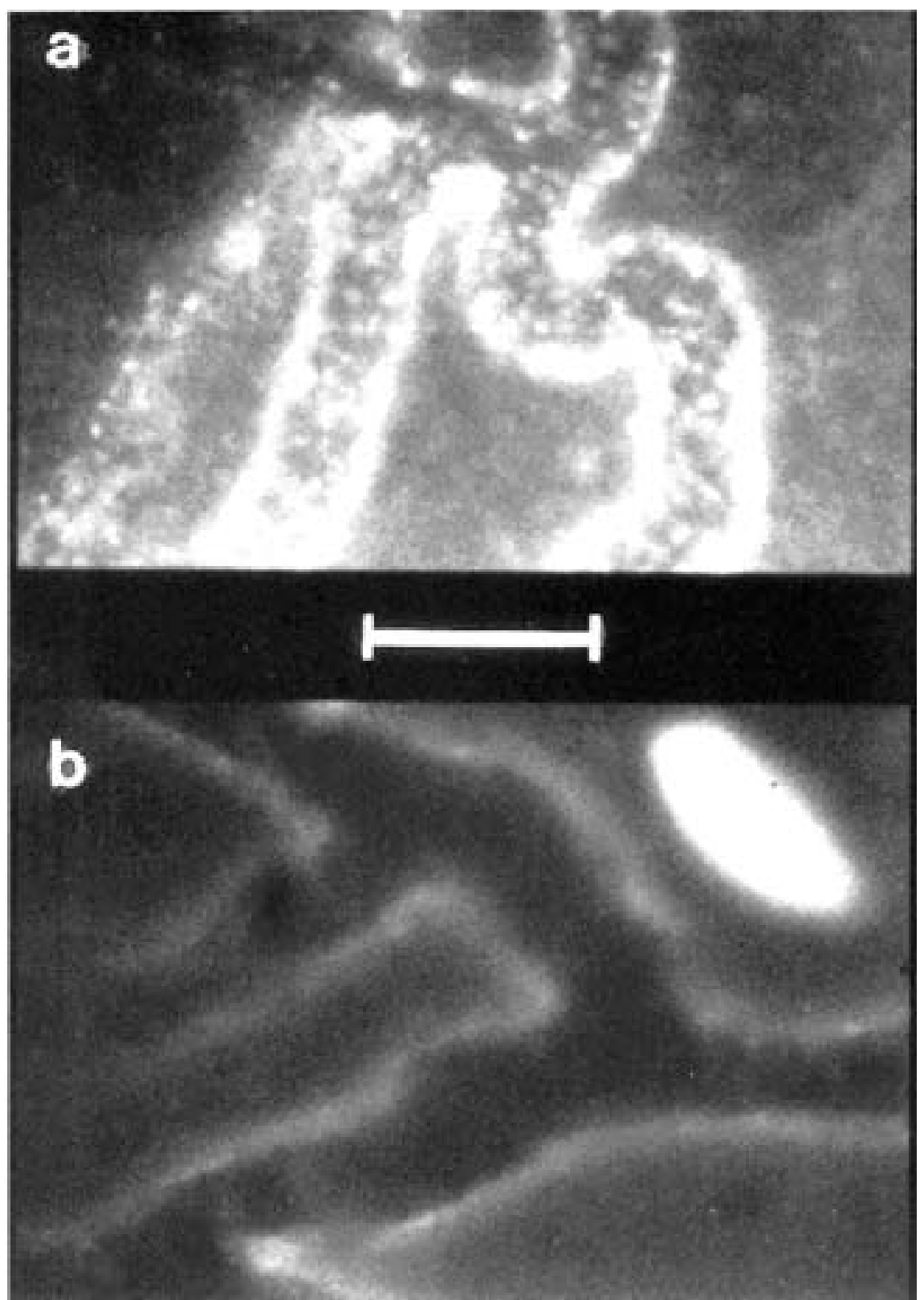

Fig. 6. Measurement of leukocyte adhesion in normal and tumor tissue in the dorsal skin fold window chamber following IV infusion of acridine orange, which stains the nuclei of circulating leukocytes. Panel a: Chamber with subcutaneous granulation tissue only. Panel b: R3230Ac mammary carcinoma tissue. Both tissues were exposed to a chemotactic peptide, fmlp, during the measurement. The granulating tissue microvessels show strong upregulation of leukocyte adhesion to vascular endothelium (indicated by bright foci adorning interior of vessels); whereas the tumor microvessels show faint staining of endothelial cells and nearby interstitium but no evidence of leukocyte-endothelial cell interactions. Figures were taken using a 2-min exposure time with a $35 \mathrm{~mm}$ camera mounted on a microscope fitted with fluorescence optics. The leukocytes are visible readily against the dark red cell-containing microvessels, which absorb light. Since this is a long exposure time, cells that did not adhere to the vascular endothelium were not observed. Bar $=100 \mu \mathrm{m}$. Figure adapted from a paper published by Wu et al. [133].

less prone to develop leukocyte-endothelial cell interactions than were microvessels of mammary tumors growing in the brain window site [130]. The mechanism for this reversal in reactivity of normal vs. tumor microvessels in this site is not known.

Additional studies have been performed to examine the consequences of radiation exposure on leukocyte endothelial cell interactions; because inflamma- 
tion is an important side effect of radiation that can cause painful, debilitating, acute side effects as well as progress to chronic normal tissue injury that can lead to severe disability. Acker et al. demonstrated that large single doses of radiation to the normal brain, as would be encountered using stereotactic radiotherapy for brain tumors or arteriovenous (AV) malformations, could lead to chronic arteritis. This was reflected as persistent upregulation of leukocyte-endothelial cell interactions in arteriolar walls at three weeks after a single radiation dose. Additionally, these lesions were shown to progress to infarcts and aneurysms in some instances [131]. Kimura et al., on the other hand, demonstrated that amelioration of these effects could be achieved by using an inhibitor of platelet-activating factor, thereby implicating this cytokine in the pathogenesis of vascular injury after radiation [132].

There are two limitations to this method. First, the dyes that are used also will label endothelial cell nuclei, so care must be taken not to confuse those with leukocytes. Second, excessive epi-illumination can lead to photobleaching and damage to vascular endothelium. This can iatrogenically increase leukocyte-endothelial cell interactions, leading to artificially elevated counts. Third, the method of quantification is somewhat controversial. Ideally, it would be best to quantify the result as the percentage of cells that either roll or adhere to vascular endothelium as compared with the leukocyte flux. However, it often is difficult to get an accurate measurement of the leukocyte flux because of poor optics or because the leukocyte flux is so high that the total numbers cannot be counted. If the results are reported in terms of raw counts of rolling or adhering cells, then it is important to verify that the systemic leukocyte counts do not differ between experimental groups. There are limitations on the size of vessel that can be studied as well. Vessels over $50 \mu \mathrm{m}$ are difficult to measure accurately because light from labelled cells at depth will be absorbed by hemoglobin.

\section{Summary}

In summary, the methods described in this review demonstrate the power of fluorescence imaging to study many features of tumor cell behavior, including participation in angiogenesis and metastasis, signal transduction, and physiologic endpoints. The future is bright for such technology to continue to facilitate the evaluation of fundamental tumor biology as well as to study efficacy of therapeutic manipulations.

\section{Acknowledgements}

This work is supported by grants from the NIH/NCICA40355 and the Duke SPORE for Breast Cancer.

\section{References}

[1] R.M. Hoffman, Orthotopic transplant mouse models with green fluorescent protein-expressing cancer cells to visualize metastasis and angiogenesis, Cancer Metast Rev 17 (1998), 271-277.

[2] R.M. Hoffman, Orthotopic metastatic mouse models for anticancer drug discovery and evaluation: a bridge to the clinic, Invest New Drugs 17 (1999), 343-359.

[3] R.K. Jain, L.L. Munn and D. Fukumura, Dissecting tumour pathophysiology using intravital microscopy, Nat Rev Cancer 2 (2002), 266-276.

[4] W.F. Jackson, Regional differences in mechanism of action of oxygen on hamster arterioles, Am J Physiol 265 (1993), H599-603.

[5] B. Klitzman, A. Popel and B. Duling, Oxygen transport in resting and contracting hamster cremaster muscles: Experimental and theoretical microvascular studies, Microvasc Res 25 (1983), 108-131.

[6] R.D. Braun, M.W. Dewhirst and D.L. Hatchell, Quantification of erythrocyte flow in the choroid of the albino rat, $A m$ J Physiol 272 (1997), H1444-1453.

[7] A.G. Tsai, B. Friesenecker, M.C. Mazzoni, H. Kerger, D.G. Buerk, P.C. Johnson and M. Intaglietta, Microvascular and tissue oxygen gradients in the rat mesentery, Proc Natl Acad Sci USA 95 (1998), 6590-6595.

[8] R.D. Braun, A. Abbas, S.O. Bukhari and W. Wilson, 3rd, Hemodynamic parameters in blood vessels in choroidal melanoma xenografts and rat choroid, Invest Ophthalmol Vis Sci 43 (2002), 3045-3052.

[9] N.J. Brown, S. Ali, M.W. Reed, R. Wiltrout and R.C. Rees, Trafficking of activated lymphocytes into the RENCA tumour microcirculation in vivo in mice, Br J Cancer 76 (1997), 1572-1578.

[10] D.A. Schuschke, M.W. Reed, J.T. Saari, M.D. Olson, D.M. Ackermann and F.N. Miller, Short-term dietary copper deficiency does not inhibit angiogenesis in tumours implanted in striated muscle, Br J Cancer 66 (1992), 1059-1064.

[11] E. Laemmel, O. Stucker, P.L. Darmon and E. Vicaut, Characterization of the specific response to serotonin of mouse tumour-feeding arterioles, Int J Radiat Biol 74 (1998), 379386.

[12] G.N. Naumov, S.M. Wilson, I.C. MacDonald, E.E. Schmidt, V.L. Morris, A.C. Groom, R.M. Hoffman and A.F. Chambers, Cellular expression of green fluorescent protein, coupled with high-resolution in vivo videomicroscopy, to monitor steps in tumor metastasis, J Cell Sci 112 (1999), 1835-1842.

[13] G. Algire, Adaptation of transparent-chamber technique to mouse, J Natl Cancer Inst 4 (1943), 1-11.

[14] D. Papenfuss, J. Gross, M. Intaglietta and F. Treese, A transparent access chamber for the rat dorsal skin fold, Microvasc Res 18 (1979), 311-318.

[15] K. Ashaishi, G. Endrich, A. Gotz and K. Messmer, Quantitative analysis of microvascular structure and function in the amelanotic melanoma A-mel-3, Cancer Res 41 (1981), 1898-1904. 
[16] M. Leunig, F. Yuan, M. Menger, Y. Boucher, A. Goetz, K. Messmer and R. Jain, Angiogenesis, microvascular architecture, microhemodynamics and interstititial fluid pressure during early growth of human adenocarcinoma LS174T in SCID mice, Cancer Res 52 (1992), 6553-6560.

[17] T. Dudar and R. Jain, Differential response of normal and tumor microcirculation to hyperthermia, Cancer Res 44 (1984), 605-612.

[18] H. Eddy and G. Casarett, Development of the vascular system in the hamster malignant neurilemmoma, Microvasc Res 6 (1973), 63-82.

[19] F. Yuan, H. Salehi, Y. Boucher, U. Vasthare, R. Tuma and R. Jain, Vascular permeability and microcirculation of gliomas and mammary carcinomas transplanted in rat and mouse cranial windows, Cancer Res 54 (1994), 4564-4568.

[20] R.M. Foltz, R.E. McLendon, H.S. Friedman, R.K. Dodge, D.D. Bigner and M.W. Dewhirst, A pial window model for the intracranial study of human glioma microvascular function, Neurosurgery 36 (1995), 976-984; discussion 984-975.

[21] Y. Tsuzuki, C. Mouta Carreira, M. Bockhorn, L. Xu, R.K. Jain and D. Fukumura, Pancreas microenvironment promotes VEGF expression and tumor growth: novel window models for pancreatic tumor angiogenesis and microcirculation, Lab Invest 81 (2001), 1439-1451.

[22] B. Endrich, B. Zweifach, H. Reinhold and M. Intaglietta, Quantitative studies of microcirculatory function in malignant tissue: influence of temperature on microvascular hemodynamics during early growth of the BA1112 rat sarcoma, Int. Radiat Onc Biol Phys 5 (1979), 2021-2030.

[23] M.W. Dewhirst, B. Klitzman, R.D. Braun, D.M. Brizel, Z.A. Haroon and T.W. Secomb, Review of methods used to study oxygen transport at the microcirculatory level, Int J Cancer 90 (2000), 237-255.

[24] O. Shimomura, F.H. Johnson and Y. Saiga, Extraction, purification and properties of Aequorin, a bioluminescent protein from the luminous Hydromedusan, Aequorea, J Cell Comp Physiol 59 (1962), 223-239.

[25] F.H. Johnson, O. Shimomura, Y. Saiga, L.C. Gershman, G.T. Reynolds and J.R. Waters, Quantum efficiency of cypridina luminescence, with a note on that of Aequorea, J Cell Comp Physiol 60 (1962), 85-103.

[26] M. Chalfie, Y. Tu, G. Euskirchen, W.W. Ward and D.C. Prasher, Green fluorescent protein as a marker for gene expression, Science 263 (1994), 802-805.

[27] B.P. Cormack, R.H. Valdivia and S. Falkow, FACS-optimized mutants of the green fluorescent protein (GFP), Gene 173 (1996), 33-38.

[28] A. Terskikh, A. Fradkov, G. Ermakova, A. Zaraisky, P. Tan, A. V. Kajava, X. Zhao, S. Lukyanov, M. Matz, S. Kim, I. Weissman and P. Siebert, "Fluorescent Timer": protein that changes color with time [In Process Citation], Science 290 (2000), 1585-1588.

[29] D. Vordermark, T. Shibata and J.M. Brown, Green fluorescent protein is a suitable reporter for tumor hypoxia despite an oxygen requirement for chromophore formation, Neoplasia 3 (2001), 527-534.

[30] M. Ikawa, K. Kominami, Y. Yoshimura, K. Tanaka, Y. Nishimune and M. Okabe, A rapid and non-invasive selection of transgenic embryos before implantation using green fluorescent protein (GFP), FEBS Lett 375 (1995), 125-128.

[31] Y.P. Wu, E. McMahon, M.R. Kraine, R. Tisch, A. Meyers, J. Frelinger, G.K. Matsushima and K. Suzuki, Distribution and characterization of GFP(+) donor hematogenous cells in Twitcher mice after bone marrow transplantation, Am $J$ Pathol 156 (2000), 1849-1854.

[32] S. Kawamoto, H. Niwa, F. Tashiro, S. Sano, G. Kondoh, J. Takeda, K. Tabayashi and J. Miyazaki, A novel reporter mouse strain that expresses enhanced green fluorescent protein upon Cre-mediated recombination, FEBS Lett 470 (2000), 263-268.

[33] D. Tannahill, S. Bray and W.A. Harris, A Drosophila E(spl) gene is "neurogenic" in Xenopus: a green fluorescent protein study, Dev Biol 168 (1995), 694-697.

[34] B.M. Tam, O.L. Moritz, L.B. Hurd and D.S. Papermaster, Identification of an outer segment targeting signal in the $\mathrm{COOH}$ terminus of rhodopsin using transgenic xenopus laevis, J Cell Biol 151 (2000), 1369-1380.

[35] A. Amsterdam, S. Lin and N. Hopkins, The Aequorea victoria green fluorescent protein can be used as a reporter in live zebrafish embryos, Dev Biol 171 (1995), 123-129.

[36] R. Rizzuto, M. Brini, P. Pizzo, M. Murgia and T. Pozzan, Chimeric green fluorescent protein as a tool for visualizing subcellular organelles in living cells, Curr Biol 5 (1995), 635-642.

[37] V.G. Thackray, R.H. Young, J.E. Hooper and S.K. Nordeen, Estrogen agonist and antagonist action on the human estrogen receptor in Drosophila [In Process Citation], Endocrinology 141 (2000), 3912-3915.

[38] C.M. Coburn and C.I. Bargmann, A putative cyclic nucleotide-gated channel is required for sensory development and function in C. elegans, Neuron 17 (1996), 695-706.

[39] C.R. Lim, Y. Kimata, M. Oka, K. Nomaguchi and K. Kohno, Thermosensitivity of green fluorescent protein fluorescence utilized to reveal novel nuclear-like compartments in a mutant nucleoporin NSP1, J Biochem (Tokyo) 118 (1995), 13-17.

[40] P. De Wulf, L. Brambilla, M. Vanoni, D. Porro and L. Alberghina, Real-time flow cytometric quantification of GFP expression and gfp- fluorescence generation in saccharomyces cerevisiae [In Process Citation], J Microbiol Methods 42 (2000), 57-64.

[41] J.R. Daum, N. Gomez-Ospina, M. Winey and D.J. Burke, The spindle checkpoint of saccharomyces cerevisiae responds to separable microtubule-dependent events [In Process Citation], Curr Biol 10 (2000), 1375-1378.

[42] B.J. Feilmeier, G. Iseminger, D. Schroeder, H. Webber and G.J. Phillips, Green fluorescent protein functions as a reporter for protein localization in Escherichia coli, J Bacteriol 182 (2000), 4068-4076.

[43] J.M. Mullaney, R.B. Thompson, Z. Gryczynski and L.W. Black, Green fluorescent protein as a probe of rotational mobility within bacteriophage T4 [In Process Citation], $J$ Virol Methods 88 (2000), 35-40.

[44] J. Chen, Y. Watanabe, N. Sako, K. Ohshima and Y. Okada, Complete nucleotide sequence and synthesis of infectious in vitro transcripts from a full-length cDNA clone of a rakkyo strain of tobacco mosaic virus, Arch Virol 141 (1996), 885900.

[45] D.M. Prescott, H.C. Charles, J.M. Poulson, R.L. Page, D.E. Thrall, Z. Vujaskovic and M.W. Dewhirst, The relationship between intracellular and extracellular $\mathrm{pH}$ in spontaneous canine tumors, Clin Cancer Res 6 (2000), 2501-2505.

[46] R. Zhou, N. Bansal, D.B. Leeper and J.D. Glickson, Intracellular acidification of human melanoma xenografts by the respiratory inhibitor m-iodobenzylguanidine plus hyperglycemia: a 31P magnetic resonance spectroscopy study, Cancer Res 60 (2000), 3532-3536. 
[47] R.J. Gillies and R.M. Lynch, Frontiers in the measurement of cell and tissue pH, Novartis Found Symp 240 (2001), 7-19.

[48] M. Okabe, M. Ikawa, K. Kominami, T. Nakanishi and Y. Nishimune, 'Green mice' as a source of ubiquitous green cells, FEBS Lett 407 (1997), 313-319.

[49] M. Sato, Y. Yasuoka, H. Kodama, T. Watanabe, J.I. Miyazaki and M. Kimura, New approach to cell lineage analysis in mammals using the Cre-loxP system, Mol Reprod Dev 56 (2000), 34-44.

[50] X.W. Yang, C. Wynder, M.L. Doughty and N. Heintz, BACmediated gene-dosage analysis reveals a role for Zipro1 (Ru49/Zfp38) in progenitor cell proliferation in cerebellum and skin, Nat Genet 22 (1999), 327-335.

[51] X.W. Yang, P. Model and N. Heintz, Homologous recombination based modification in Escherichia coli and germline transmission in transgenic mice of a bacterial artificial chromosome, Nat Biotechnol 15 (1997), 859-865.

[52] J. Zuo, J. Treadaway, T.W. Buckner and B. Fritzsch, Visualization of alpha9 acetylcholine receptor expression in hair cells of transgenic mice containing a modified bacterial artificial chromosome, Proc Natl Acad Sci USA 96 (1999), 14100-14105.

[53] S. Kupzig, Methods in Enzymology, (Vol. 302), Academic Press, San Diego, 1999.

[54] S.J. Scales, R. Pepperkok and T.E. Kreis, Visualization of ER-to-Golgi transport in living cells reveals a sequential mode of action for COPII and COPI, Cell 90 (1997), 11371148.

[55] A. Cornea, J.A. Janovick, X. Lin and P.M. Conn, Simultaneous and independent visualization of the gonadotropinreleasing hormone receptor and its ligand: evidence for independent processing and recycling in living cells [published erratum appears in Endocrinology 1999 Oct;140(10):4771], Endocrinology 140 (1999), 4272-4280.

[56] A. Miyawaki, J. Llopis, R. Heim, J.M. McCaffery, J.A. Adams, M. Ikura and R.Y. Tsien, Fluorescent indicators for $\mathrm{Ca}^{2+}$ based on green fluorescent proteins and calmodulin [see comments], Nature 388 (1997), 882-887.

[57] X. Xu, A.L. Gerard, B.C. Huang, D.C. Anderson, D.G. Payan and Y. Luo, Detection of programmed cell death using fluorescence energy transfer, Nucleic Acids Res 26 (1998), 20342035.

[58] R. Heim and R.Y. Tsien, Engineering green fluorescent protein for improved brightness, longer wavelengths and fluorescence resonance energy transfer, Curr Biol 6 (1996), 178182.

[59] G. Imreh, M. Beckman, K. Iverfeldt and E. Hallberg, Noninvasive monitoring of apoptosis versus necrosis in a neuroblastoma cell line expressing a nuclear pore protein tagged with the green fluorescent protein, Exp Cell Res 238 (1998), 371-376.

[60] W. Zhang, S. Labrecque, E. Azoulay, R. Dudley and G. Matlashewski, Development of a p53 responsive GFP reporter; identification of live cells with p53 activity, J Biotechnol $\mathbf{8 4}$ (2000), 79-86.

[61] C.Y. Li, S. Shan, Q. Huang, R.D. Braun, J. Lanzen, K. Hu, P. Lin and M.W. Dewhirst, Initial stages of tumor cell-induced angiogenesis: evaluation via skin window chambers in rodent models, J Natl Cancer Inst 92 (2000), 143-147.

[62] D. Fukumura, R. Xavier, T. Sugiura, Y. Chen, E.C. Park, N. Lu, M. Selig, G. Nielsen, T. Taksir, R.K. Jain and B. Seed, Tumor induction of VEGF promoter activity in stromal cells, Cell 94 (1998), 715-725.
[63] T. Motoike, S. Loughna, E. Perens, B.L. Roman, W. Liao, T.C. Chau, C.D. Richardson, T. Kawate, J. Kuno, B.M. Weinstein, D.Y. Stainier and T.N. Sato, Universal GFP reporter for the study of vascular development, Genesis 28 (2000), $75-81$.

[64] L. Xu, D. Fukumura and R.K. Jain, Acidic extracellular pH induces vascular endothelial growth factor (VEGF) in human glioblastoma cells via ERK1/2 MAPK signaling pathway: mechanism of low pH-induced VEGF, J Biol Chem 277 (2002), 11368-11374.

[65] D. Fukumura, L. Xu, Y. Chen, T. Gohongi, B. Seed and R.K. Jain, Hypoxia and acidosis independently up-regulate vascular endothelial growth factor transcription in brain tumors in vivo, Cancer Res 61 (2001), 6020-6024.

[66] M. Kneen, J. Farinas, Y. Li and A.S. Verkman, Green fluorescent protein as a noninvasive intracellular $\mathrm{pH}$ indicator, Biophys J 74 (1998), 1591-1599.

[67] J.S. Condeelis, J. Wyckoff and J.E. Segall, Imaging of cancer invasion and metastasis using green fluorescent protein [In Process Citation], Eur J Cancer 36 (2000), 1671-1680.

[68] T. Chishima, M. Yang, Y. Miyagi, L. Li, Y. Tan, E. Baranov, H. Shimada, A.R. Moossa, S. Penman and R.M. Hoffman, Governing step of metastasis visualized in vitro, Proc Natl Acad Sci USA 94 (1997), 11573-11576.

[69] T. Chishima, Y. Miyagi, X. Wang, E. Baranov, Y. Tan, H. Shimada, A.R. Moossa and R.M. Hoffman, Metastatic patterns of lung cancer visualized live and in process by green fluorescence protein expression, Clin Exp Metastasis 15 (1997), 547-552.

[70] T. Chishima, Y. Miyagi, X. Wang, Y. Tan, H. Shimada, A. Moossa and R.M. Hoffman, Visualization of the metastatic process by green fluorescent protein expression, Anticancer Res 17 (1997), 2377-2384.

[71] T. Chishima, Y. Miyagi, X. Wang, H. Yamaoka, H. Shimada, A.R. Moossa and R.M. Hoffman, Cancer invasion and micrometastasis visualized in live tissue by green fluorescent protein expression, Cancer Res 57 (1997), 2042-2047.

[72] S. Hasegawa, M. Yang, T. Chishima, Y. Miyagi, H. Shimada, A.R. Moossa and R.M. Hoffman, In vivo tumor delivery of the green fluorescent protein gene to report future occurrence of metastasis, Cancer Gene Ther 7 (2000), 1336-1340.

[73] M. Yang, P. Jiang, Z. An, E. Baranov, L. Li, S. Hasegawa, M. Al-Tuwaijri, T. Chishima, H. Shimada, A.R. Moossa and R.M. Hoffman, Genetically fluorescent melanoma bone and organ metastasis models, Clin Cancer Res 5 (1999), 35493559.

[74] M. Yang, P. Jiang, F.X. Sun, S. Hasegawa, E. Baranov, T. Chishima, H. Shimada, A.R. Moossa and R.M. Hoffman, A fluorescent orthotopic bone metastasis model of human prostate cancer, Cancer Res 59 (1999), 781-786.

[75] M. Bouvet, J. Wang, S.R. Nardin, R. Nassirpour, M. Yang, E. Baranov, P. Jiang, A.R. Moossa and R.M. Hoffman, Realtime optical imaging of primary tumor growth and multiple metastatic events in a pancreatic cancer orthotopic model, Cancer Res 62 (2002), 1534-1540.

[76] X. Li, J. Wang, Z. An, M. Yang, E. Baranov, P. Jiang, F. Sun, A.R. Moossa and R.M. Hoffman, Optically imageable metastatic model of human breast cancer, Clin Exp Metastasis 19 (2002), 347-350.

[77] A.B. Al-Mehdi, K. Tozawa, A.B. Fisher, L. Shientag, A. Lee and R.J. Muschel, Intravascular origin of metastasis from the proliferation of endothelium-attached tumor cells: a new model for metastasis, Nat Med 6 (2000), 100-102. 
[78] C.W. Wong, C. Song, M.M. Grimes, W. Fu, M.W. Dewhirst, R.J. Muschel and A.B. Al-Mehdi, Intravascular location of breast cancer cells after spontaneous metastasis to the lung, Am J Pathol 161 (2002), 749-753.

[79] Q. Huang, S. Shan, R.D. Braun, J. Lanzen, G. Anyrhambatla, G. Kong, M. Borelli, P. Corry, M.W. Dewhirst and C.Y. Li, Noninvasive visualization of tumors in rodent dorsal skin window chambers, Nat Biotechnol 17 (1999), 1033-1035.

[80] F. Rolling, W.Y. Shen, N.L. Barnett, H. Tabarias, Y. Kanagasingam, I. Constable and P.E. Rakoczy, Long-term realtime monitoring of adeno-associated virus-mediated gene expression in the rat retina, Clin Experiment Ophthalmol 28 (2000), 382-386.

[81] T.R. Flotte, S.E. Beck, K. Chesnut, M. Potter, A. Poirier and S. Zolotukhin, A fluorescence video-endoscopy technique for detection of gene transfer and expression, Gene Ther $\mathbf{5}$ (1998), 166-173.

[82] C.Y. Li, J.B. Little, K. Hu, W. Zhang, L. Zhang, M.W. Dewhirst and Q. Huang, Persistent genetic instability in cancer cells induced by non-DNA- damaging stress exposures, Cancer Res 61 (2001), 428-432.

[83] L.K. Fung and W.M. Saltzman, Polymeric implants for cancer chemotherapy, Advanced Drug Delivery Reviews 26 (1997), 209-230.

[84] W. Dang, O.M. Colvin, H. Brem and W.M. Saltzman, Covalent coupling of methotrexate to dextran enhances the penetration of cytotoxicity into a tissue-like matrix, Cancer Res 54 (1994), 1729-1735.

[85] F. Yuan, M. Leunig, D.A. Berk and R.K. Jain, Microvascular permeability of albumin, vascular surface area, and vascular volume measured in human adenocarcinoma LS174T using dorsal chamber in SCID mice, Microvasc Res 45 (1993), 269-289.

[86] N.Z. Wu, B. Klitzman, G. Rosner, D. Needham and M.W. Dewhirst, Measurement of material extravasation in microvascular networks using fluorescence video-microscopy, $\mathrm{Mi}$ crovasc Res 46 (1993), 231-253.

[87] L.E. Gerlowski and R.K. Jain, Microvascular permeability of normal and neoplastic tissues, Microvasc Res 31 (1986), 288-305.

[88] H.C. Lichtenbeld, F. Yuan, C.C. Michel and R.K. Jain, Perfusion of single tumor microvessels: application to vascular permeability measurement, Microcirculation 3 (1996), 349357.

[89] D.A. Berk, F. Yuan, M. Leunig and R.K. Jain, Fluorescence photobleaching with spatial Fourier analysis: measurement of diffusion in light-scattering media, Biophys J 65 (1993), 2428-2436.

[90] S.R. Chary and R.K. Jain, Direct measurement of interstitial diffusion and convection of albumin in normal and neoplastic tissues using fluorescence photobleaching, PNAS 86 (1989), 5385-5389.

[91] L.J. Nugent and R.K. Jain, Plasma pharmacokinetics and interstitial diffusion of macromolecules in a capillary bed, Am J Physiol 246 (1984), H129-137.

[92] A. Pluen, Y. Boucher, S. Ramanujan, T.D. McKee, T. Gohongi, E. di Tomaso, E.B. Brown, Y. Izumi, R.B. Campbell, D.A. Berk and R.K. Jain, Role of tumor-host interactions in interstitial diffusion of macromolecules: Cranial vs. subcutaneous tumors, Proc Natl Acad Sci USA 98 (2001), 4628-4633.

[93] D.A. Berk, F. Yuan, M. Leunig and R.K. Jain, Direct in vivo measurement of targeted binding in a human tumor xenograft, Proc Natl Acad Sci USA 94 (1997), 1785-1790.
[94] D. Brizel, B. Klitzman, J. Cook, J. Edwards, G. Rosner and $\mathrm{M}$. Dewhirst, A comparison of tumor and normal tissue microvascular hematocrits and red cell fluxes in a rat window chamber model, Int. J Radia. Oncol Biol Phys 25 (1993), 269-276.

[95] N.Z. Wu and A.L. Baldwin, Possible mechanism(s) for permeability recovery of venules during histamine application, Microvasc Res 44 (1992), 334-352.

[96] N.Z. Wu and A.L. Baldwin, Transient venular permeability increase and endothelial gap formation induced by histamine, Am J Physiol 262 (1992), H1238-1247.

[97] F.E. Curry, Regulation of water and solute exchange in microvessel endothelium: studies in single perfused capillaries, Microcirculation 1 (1994), 11-26.

[98] R.H. Adamson, J.F. Lenz and F.E. Curry, Quantitative laser scanning confocal microscopy on single capillaries: permeability measurement, Microcirculation 1 (1994), 251-265.

[99] E.B. Brown, R.B. Campbell, Y. Tsuzuki, L. Xu, P. Carmeliet, D. Fukumura and R.K. Jain, In vivo measurement of gene expression, angiogenesis and physiological function in tumors using multiphoton laser scanning microscopy, Nat Med 7 (2001), 864-868.

[100] D. Axelrod, D.E. Koppel, J. Schlessinger, E. Elson and W.W. Webb, Mobility measurement by analysis of fluorescence photobleaching recovery kinetics, Biophys J16 (1976), 1055-1069.

[101] L.J. Nugent and R.K. Jain, Extravascular diffusion in normal and neoplastic tissues, Cancer Res 44 (1984), 238-244.

[102] D. Fukumura, F. Yuan, M. Endo and R.K. Jain, Role of nitric oxide in tumor microcirculation. Blood flow, vascular permeability, and leukocyte-endothelial interactions, Am J Pathol 150 (1997), 713-725.

[103] D. Fukumura, F. Yuan, W.L. Monsky, Y. Chen and R.K. Jain, Effect of host microenvironment on the microcirculation of human colon adenocarcinoma, Am J Pathol 151 (1997), 679688.

[104] G. Kong, R.D. Braun and M.W. Dewhirst, Hyperthermia enables tumor-specific nanoparticle delivery: effect of particle size, Cancer Res 60 (2000), 4440-4445.

[105] F. Yuan, M. Dellian, D. Fukumura, M. Leunig, D.A. Berk, V.P. Torchilin and R.K. Jain, Vascular permeability in a human tumor xenograft: molecular size dependence and cutoff size, Cancer Res 55 (1995), 3752-3756.

[106] S.K. Hobbs, W. Monsky, F. Yuan, W.G. Roberts, L. Griffith, V.P. Torchillin and R.K. Jain, Regulation of transport pathways in tumor vessels: Role of tumor type and microenvironment, Proc Nat Acad Sci USA 95 (1998), 4607-4612.

[107] G. Kong, R.D. Braun and M.W. Dewhirst, Characterization of the effect of hyperthermia on nanoparticle extravasation from tumor vasculature, Cancer Res 61 (2001), 3027-3032.

[108] D.E. Meyer, G.A. Kong, M.W. Dewhirst, M.R. Zalutsky and A. Chilkoti, Targeting a genetically engineered elastin-like polypeptide to solid tumors by local hyperthermia, Cancer Res 61 (2001), 1548-1554.

[109] M. Dewhirst, H. Kimura, S. Rehmus, R. Braun, D. Papahadjopoulos, K. Hong and T. Secomb, Microvascular studies on the origins of perfusion-limited hypoxia, Bri. J Cancer $\mathbf{7 4}$ (1996), S247-S251.

[110] H. Kimura, R.D. Braun, E.T. Ong, R. Hsu, T.W. Secomb, D. Papahadjopoulos, K. Hong and M.W. Dewhirst, Fluctuations in red cell flux in tumor microvessels can lead to transient hypoxia and reoxygenation in tumor parenchyma, Cancer Res 56 (1996), 5522-5528. 
[111] J. Unthank, J. Lash, J. Nixon, R. Sidner and H. Bohlen, Evaluation of carbocyanine-labeled erythrocytes for microvascular measurements, Microvasc Res 45 (1993), 193-210.

[112] G.R. Martin and R.K. Jain, Noninvasive measurement of interstitial $\mathrm{pH}$ profiles in normal and neoplastic tissue using fluorescence ratio imaging microscopy, Cancer Res 54 (1994), 5670-5674.

[113] G.R. Martin and R.K. Jain, Fluorescence ratio imaging measurement of $\mathrm{pH}$ gradients: calibration and application in normal and tumor tissues, Microvasc Res 46 (1993), 216-230.

[114] G. Helmlinger, F. Yuan, M. Dellian and R.K. Jain, Interstitial $\mathrm{pH}$ and $\mathrm{pO} 2$ gradients in solid tumors in vivo: high-resolution measurements reveal a lack of correlation, Nat Med 3 (1997), $177-182$.

[115] S.A. Vinogradov and D.F. Wilson, Recovery of oxygen distributions in tissue from phosphorescence decay data, $A d v$ Exp Med Biol 361 (1994), 67-73.

[116] D.F. Wilson and S.A. Vinogradov, Recent advances in oxygen measurements using phosphorescence quenching, Adv Exp Med Biol 361 (1994), 61-66.

[117] S.A. Vinogradov and D.F. Wilson, Phosphorescence lifetime analysis with a quadratic programming algorithm for determining quencher distributions in heterogeneous systems, Biophys J 67 (1994), 2048-2059.

[118] S.A. Vinogradov, L.W. Lo, W.T. Jenkins, S.M. Evans, C. Koch and D.F. Wilson, Noninvasive imaging of the distribution in oxygen in tissue in vivo using near-infrared phosphors, Biophys J 70 (1996), 1609-1617.

[119] I.P. Torres Filho, M. Leunig, F. Yuan, M. Intaglietta and R.K. Jain, Noninvasive measurement of microvascular and interstitial oxygen profiles in a human tumor in SCID mice, Proc Natl Acad Sci USA 91 (1994), 2081-2085.

[120] M.W. Dewhirst, E.T. Ong, R.D. Braun, B. Smith, B. Klitzman, S.M. Evans and D. Wilson, Quantification of longitudinal tissue pO2 gradients in window chamber tumours: impact on tumour hypoxia, Br J Cancer 79 (1999), 1717-1722.

[121] T.M. Carlos and J.M. Harlan, Leukocyte-endothelial adhesion molecules, Blood 84 (1994), 2068-2101.

[122] M.J. Eppihimer and D.N. Granger, Ischemia/reperfusioninduced leukocyte-endothelial interactions in postcapillary venules, Shock 8 (1997), 16-25.

[123] C. Ohkubo, D. Bigos and R.K. Jain, Interleukin 2 induced leukocyte adhesion to the normal and tumor microvascular endothelium in vivo and its inhibition by dextran sulfate: implications for vascular leak syndrome, Cancer Res $\mathbf{5 1}$ (1991), 1561-1563.

[124] A. Sasaki, R.J. Melder, T.L. Whiteside, R.B. Herberman and R.K. Jain, Preferential localization of human adherent lymphokine-activated killer cells in tumor microcirculation, J Natl Cancer Inst 83 (1991), 433-437.

[125] M.W. Dewhirst, R.Z. Vinuya, E.T. Ong, B. Klitzman, G. Rosner, T.W. Secomb and J.F. Gross, Effects of bradykinin on the hemodynamics of tumor and granulating normal tissue microvasculature, Radiat Res 130 (1992), 345-354.

[126] N.Z. Wu, B.A. Ross, C. Gulledge, B. Klitzman, R. Dodge and M.W. Dewhirst, Differences in leucocyte-endothelium interactions between normal and adenocarcinoma bearing tissues in response to radiation, Br J Cancer 69 (1994), 883889.

[127] R.J. Melder, G.C. Koenig, B.P. Witwer, N. Safabakhsh, L.L. Munn and R.K. Jain, During angiogenesis, vascular endothelial growth factor and basic fibroblast growth factor regulate natural killer cell adhesion to tumor endothelium [see comments], Nat Med 2 (1996), 992-997.

[128] D. Fukumura, F. Yuan, W.L. Monsky, Y. Chen and R.K. Jain, Effect of host microenvironment on the microcirculation of human colon adenocarcinoma, Am J Pathol 151 (1997), 679688.

[129] R.K. Jain, G.C. Koenig, M. Dellian, D. Fukumura, L.L. Munn and R.J. Melder, Leukocyte-endothelial adhesion and angiogenesis in tumors, Cancer Metast Rev 15 (1996), 195-204.

[130] R.J. Melder, H.A. Salehi and R.K. Jain, Interaction of activated natural killer cells with normal and tumor vessels in cranial windows in mice, Microvasc Res 50 (1995), 35-44.

[131] J.C. Acker, L.B. Marks, D.P. Spencer, W. Yang, M.A. Avery, R.K. Dodge, G.L. Rosner and M.W. Dewhirst, Serial in vivo observations of cerebral vasculature after treatment with a large single fraction of radiation, Radiat Res 149 (1998), $350-359$.

[132] H. Kimura, N.Z. Wu, R. Dodge, D.P. Spencer, B.M. K1itzman, T.M. McIntyre and M.W. Dewhirst, Inhibition of radiation-induced up-regulation of leukocyte adhesion to endothelial cells with the platelet-activating factor inhibitor, BN52021, Int J Radiat Oncol Biol Phys 33 (1995), 627-633.

[133] N.Z. Wu, B. Klitzman, R. Dodge and M.W. Dewhirst, Diminished leukocyte-endothelium interaction in tumor microvessels, Cancer Res 52 (1992), 4265-4268. 


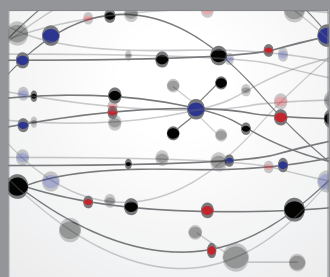

The Scientific World Journal
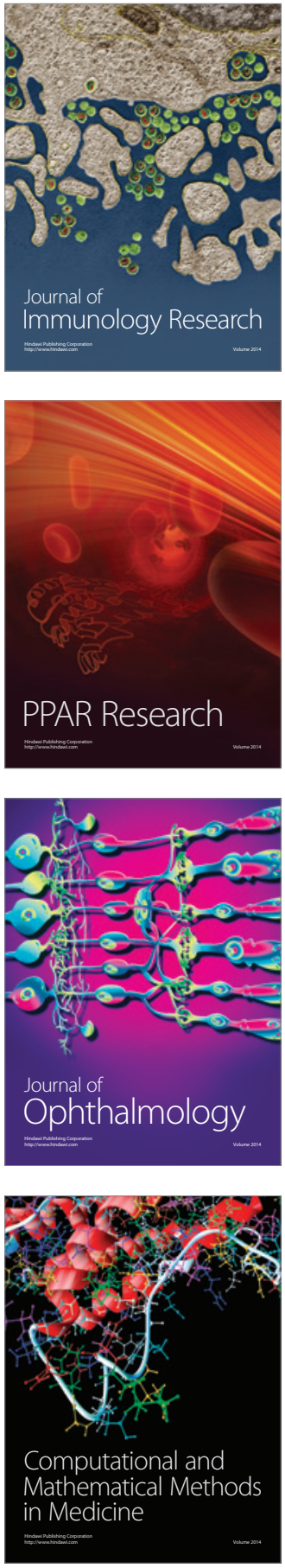

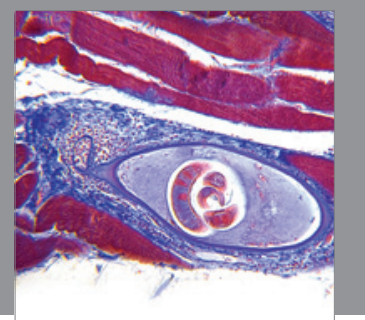

Gastroenterology

Research and Practice
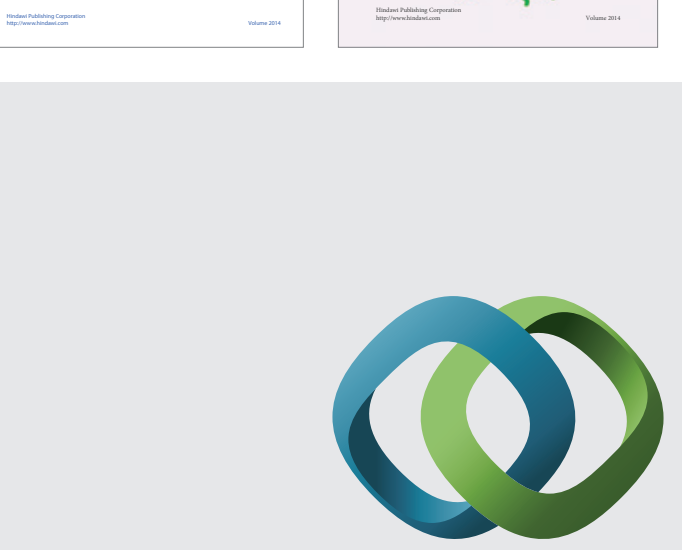

\section{Hindawi}

Submit your manuscripts at

http://www.hindawi.com
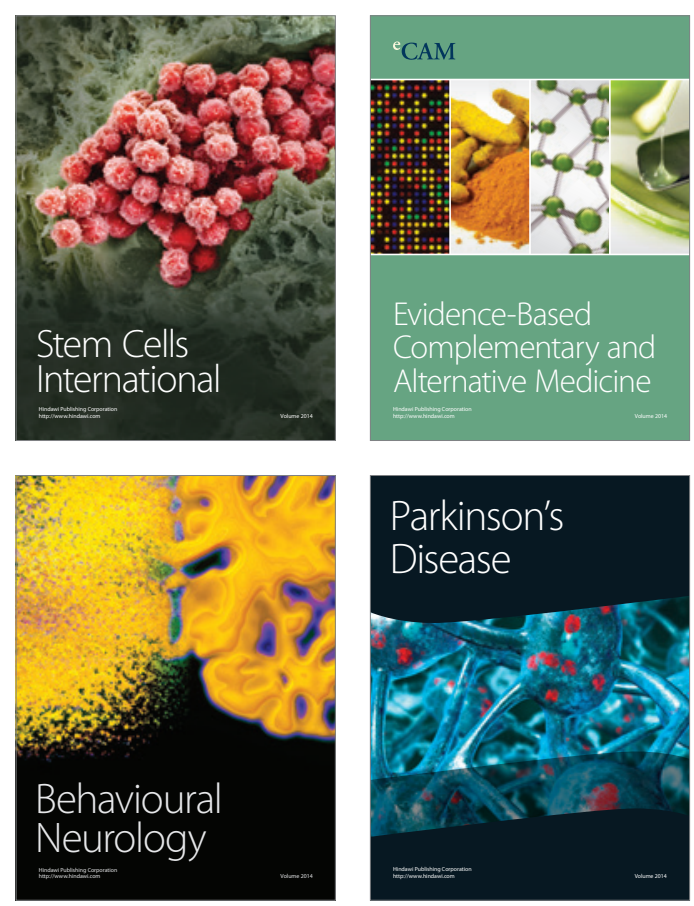

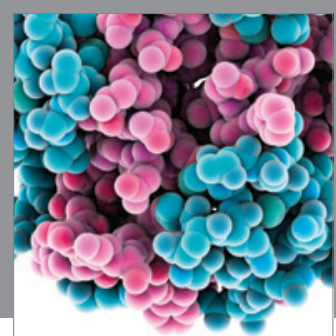

Journal of
Diabetes Research

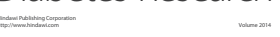

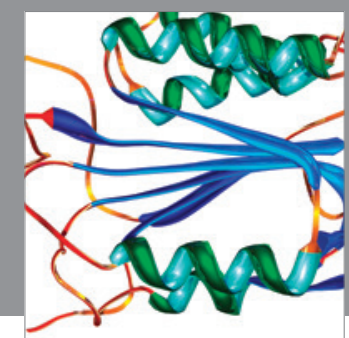

Disease Markers
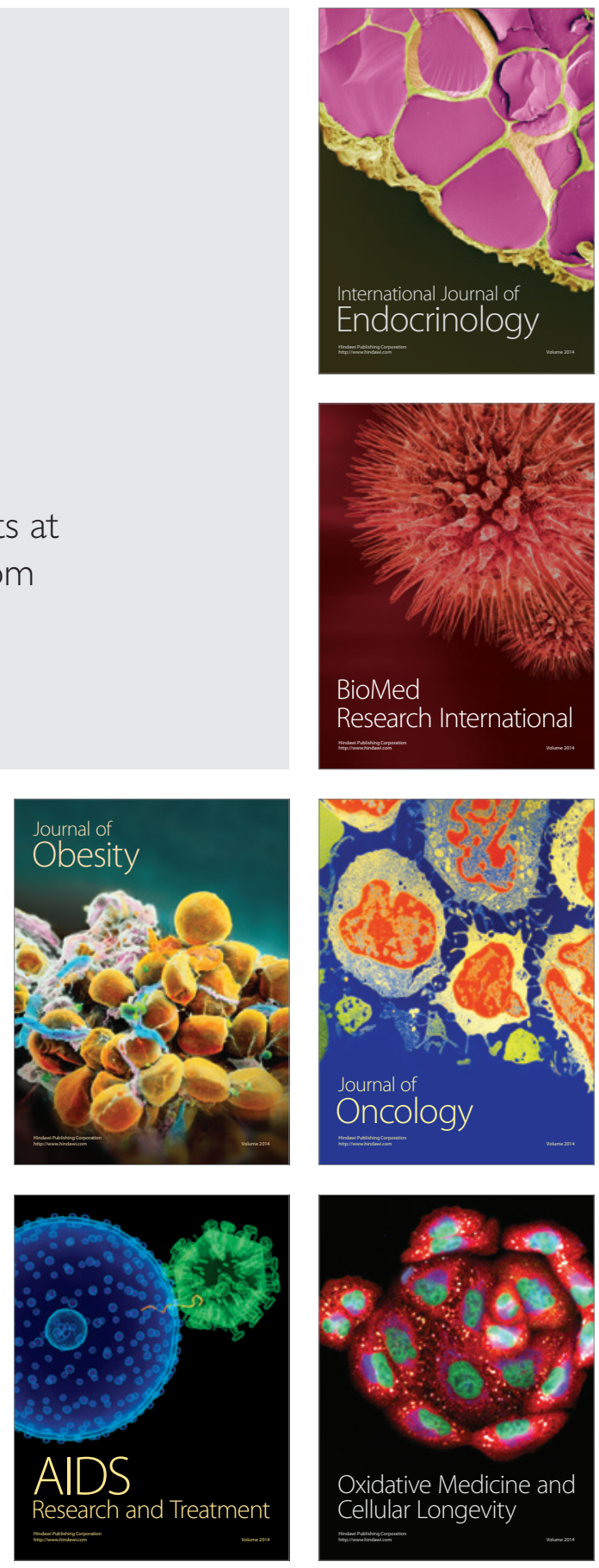